\title{
Biomarkers in Epilepsy
}

Asla Pitkänen ${ }^{1}$, Wolfgang Löscher ${ }^{2}$, Annamaria Vezzani ${ }^{3}$, Albert J. Becker ${ }^{4}$, Michele Simonato ${ }^{5}$, Katarzyna Lukasiuk ${ }^{6}$, Olli Gröhn ${ }^{7}$, Jens P. Bankstahl ${ }^{8}$,AlonFriedman ${ }^{9}$, Eleonora Aronica ${ }^{10}$, Jan A. Gorter $^{11}$, Teresa Ravizza ${ }^{12}$, Sanjay Sisodiya ${ }^{13}$, Merab Kokaia ${ }^{14}$, Heinz Beck ${ }^{15}$

\begin{abstract}
${ }^{1}$ Asla Pitkänen, PhD, Department of Neurobiology, A. I. Virtanen Institute for Molecular Sciences, University of Eastern Finland, P.O. Box 1627, FIN-70 211, Kuopio, Finland. E-mail: asla.Pitkänen@uef.fi.

${ }^{2}$ Wolfgang Löscher, PhD, Department of Pharmacology, Toxicology and Pharmacy, University of Veterinary Medicine, D-30559 Hannover, Germany; and Center for Systems Neuroscience, D-30559 Hannover, Germany. E-mail: wolfgang.loescher@tiho-hannover.de.

${ }^{3}$ Annamaria Vezzani, PhD, Department of Neuroscience (Experimental Neurology) - Istituto di Recerche Farmacologiche 'Mario Negri' Milan, Italy. E-mail: annamaria.vezzani@marionegri.it.

${ }^{4}$ Albert J Becker, MD, Section for Translational Epilepsy Research, Department of Neuropathology, University of Bonn Medical Center, Sigmund-Freud Str. 25, D-53105 Bonn, Germany. E-mail: albert becker@uni-bonn.de.
\end{abstract}

${ }^{5}$ Michele Simonato, MD, Department of Medical Sciences (Section of Pharmacology), University of Ferrara, Ferrara, and Unit of Gene therapy of neurodegenerative diseases, Division of Neuroscience, IRCCS San Raffaele Scientific Institute, Milan, Italy. E-mail: michele.simonato@unife.it.

${ }^{6}$ KatarzynaLukasiuk, PhD, The Nencki Institute of Experimental Biology, Polish Academy of Sciences, 3 Pasteur St, 02-093 Warsaw, Poland. E-mail: k.lukasiuk@nencki.gov.pl.

${ }^{7}$ Olli Gröhn, PhD, Department of Neurobiology, A. I. Virtanen Institute for Molecular Sciences, University of Eastern Finland, P.O. Box 1627, FIN-70 211, Kuopio, Finland. E-mail: olli.gröhn@uef.fi.

${ }^{8}$ Jens P. Bankstahl, PhD, Preclinical Molecular Imaging, Department of Nuclear Medicine, Hannover Medical School, Carl-Neuberg-Str. 1, 30625 Hannover, Germany. E-mail: bankstahl.jens@mhhannover.de.

${ }^{9}$ Alon Friedman, PhD. Department of Brain and Cognitive Sciences, Zlotowski Center for Neuroscience, Ben-Gurion University of the Negev, Israel and Department of Medical Neuroscience, Dalhousie University, Halifax, NS. E-mail: alonf@bgu.ac.il.

${ }^{10}$ Eleonora Aronica, MD, Department of (Neuro)Pathology, Academic Medical Center and Swammerdam Institute for Life Sciences, Center for Neuroscience, University of Amsterdam, The 
Netherlands and SEIN - Stichting Epilepsie Instellingen Nederland, Heemstede, The Netherlands. Email: e.aronica@amc.uva.nl.

${ }^{11}$ Jan A. Gorter, PhD, Swammerdam Institute for Life Sciences, Center for Neuroscience, University of Amsterdam, The Netherlands. E-mail: J.A.Gorter@uva.nl.

${ }^{12}$ Teresa Ravizza, PhD, Department of Neuroscience (Experimental Neurology) - Istituto di Recerche Farmacologiche 'Mario Negri' Milan, Italy. E-mail: teresa. ravizza@marionegri.it.

${ }^{13}$ Sanjay Sisodiya PhD FRCP. Department of Clinical and Experimental Epilepsy, UCL Institute of Neurology, Queen Square, London, UK. E-mail: s.sisodiya@ucl.ac.uk.

${ }^{14}$ Merab Kokaia, PhD, Epilepsy Center (Experimental Epilepsy Group), Division of Neurology, Department of Clinical Sciences, Lund University Hospital, Lund, Sweden. E-mail: merab.kokaia@med.lu.se.

${ }^{15}$ Heinz Beck, Laboratory for Experimental Epileptology and Cognition Research, Department of Epileptology, University of Bonn, Sigmund-Freud-Straße 25, 53105 Bonn, Germany, and German Center for Neurodegenerative Diseases (DZNE), Ludwig-Erhard-Allee 2, 53175 Bonn, E-mail: heinz.beck@ukb.uni-bonn.de“

Corresponding author: Dr. Heinz Beck, Laboratory for Experimental Epileptology and Cognition Research, Department of Epileptology, University of Bonn, Sigmund-Freud-Straße 25, 53105 Bonn. Email: heinz.beck@ukb.uni-bonn.de“

Contributions: The review was envisioned and planned as a collaborative activity within the EU consortium EPITARGET, of which all authors are members. All authors contributed equally to the conception, design, literature search, and writing of this review.

Conflicts of interest: We declare that we have no conflicts of interest.

Acknowledgements: This study was primarily supported by the FP7-HEALTH project 602102 (EPITARGET, all authors);The Academy of Finland (AP); Polish Ministry of Science and Education W19/7.PR/2014 (KL); Fondazione Monzino and CURE (AV, TR); The Niedersachsen-Research Network 
on Neuroinfectiology (N-RENNT) of the Ministry of Science and Culture of Lower Saxony, Germany (WL); The Israel Science Foundation (AF); FP7-PEOPLE-2011-IAPP project 285827 (EPIXCHANGE)(MS and MK) and SFB1089 of the DFG (AB and HB)

Search Strategy and selection criteria: We searched all PubMed articles published up to November 2015, with the terms "biomarker", "epilepsy", "seizure", "seizure threshold", "epileptogenesis", "antiepileptogenesis", "imaging biomarker", "co-morbidity", and their combinations. Data from experimental and clinical studies were included. For genetics we performed searches using the terms "polymorphism and epilepsy", "polymorphism and epilepsy and outcome". Articles were also identified through searches of the authors' own article collections. Only articles published in English were reviewed. 


\begin{abstract}
Over 50 million people world-wide have epilepsy. Nearly $30 \%$ of these cases remain unsatisfactorily controlled despite $>20$ antiepileptic drugs available on the market. Moreover, no treatments exist to prevent the development of epilepsy in those at risk for epileptogenesis due to any cause. In spite of more than 30 promising preclinical proof-of-concept studies showing antiepileptogenic effects of various treatments, there has been no translation of these preclinical developments to the clinical arena. The development of anti-epileptogenic treatments has been hampered by the estimated high cost of clinical studies as there are no biomarkers available that could be used to stratify patients to design an affordable, adequately powered study. In addition to the need for biomarkers of epileptogenesis, the epilepsy field needs diagnostic and progression markers. The former would be useful to confirm an epilepsy diagnosis after the first unprovoked seizure, to recognize cure after epilepsy surgery or remission after treatment discontinuation. The latter should predict treatment response, progression of epilepsy, severity of epilepsy, and development of epilepsy-related co-morbidities. We review the recent studies providing proof-ofconcept evidence that identification and use of single or combinatory biomarkers derived from analysis of electrophysiological, imaging or blood markers in epilepsy is feasible, and outline the challenges ahead.
\end{abstract}




\section{Background}

More than 50 million people world-wide have epilepsy and an estimated 2.4 million people are newly diagnosed with epilepsy each year (http://www.who.int/mediacentre/factsheets/fs999/en/). However, despite the availability of $>20$ antiepileptic (anti-seizure) drugs, seizures remain uncontrolled in $\sim 30 \%$ of people with epilepsy (PWE). Considerable attention has focused on increasing the efficacy of anti-seizure drugs with fewer adverse effects ${ }^{1}$. In addition, there is an increasing awareness of the need to identify the individuals who are at risk of developing epilepsy, and to develop preventive or disease-modifying treatments for these groups.

One major impediment to reaching these goals is the heterogeneity of epilepsies. Multiple different etiologies, or combinations of factors can underlie an increased disposition to generate seizures. Amongst these are genetic factors, different forms of brain insults such as stroke, traumatic brain injury (TBI) or peri- and prenatal injury, as well as CNS malformations or tumors. Clearly, this broad spectrum of disease entities implies a large spectrum of mechanisms that lead to establishment of an epileptogenic focus, and also potentially diverse mechanisms of functional impairment and seizure generation. Moreover, even in those comparatively homogeneous groups of PWE in which an initial injury can be precisely determined, such as stroke or TBI, only $<20 \%$ of patients will develop epilepsy within a 1-2 year follow-up ${ }^{2}$, implying further, intra-syndrome heterogeneity. Accordingly, there is an increasing awareness that both anti-seizure and anti-epileptogenic treatments have to be guided on an individualized basis. This is particularly true for anti-epileptogenic treatments, which would ideally require predicting which individual patients with an initial injury will later develop epilepsy. Identification of biomarkers that can help in guiding diagnosis and therapy has therefore been at the center stage of research efforts in the last years. An advantage in these efforts is that the medical evaluation of patients with first-time seizures or initial injuries is frequently detailed, and thus detailed clinicopathological data are available.

The consensus definition of the International League against Epilepsy defines a biomarker for epileptogenesis as an objectively measurable characteristic of a biological process that reliably identifies the development, presence, severity, progression, or localization of an epileptogenic abnormality. An epileptogenic abnormality refers to the pathophysiological substrate(s) responsible 
for the initiation and/or maintenance of epilepsy ${ }^{3}$. This rather dry definition nevertheless captures the important features of the epilepsies that would profit greatly from the availability of diagnostic or prognostic biomarkers. Diagnostic biomarkers in this context yield information about the current clinical status, such as i.e. the extent and localization of the epileptogenic area, or the severity of epilepsy. They may also yield information about sensitivity of the current clinical symptoms to specific treatments.

Prognostic biomarkers are both of clinically high potential relevance and more problematic to identify. They are defined as those biomarkers that allow prediction of future clinical features on an individual basis. They thus report on features of the development or progression of epilepsy, a process termed epileptogenesis ${ }^{3,4,5}$. This term refers to a process whereby CNS tissue acquires the capability to generate spontaneous seizures. In addition to unprovoked seizures, epilepsy is also often associated with somatic, cognitive, psychiatric, and behavioral co-morbidities ${ }^{6,7,8}$. The evolution of these co-morbidities is also an important feature of epileptogenesis. Thus, prognostic biomarkers could yield useful information that epilepsy will develop in the presence of risk factors, the speed of progression or severity of epilepsy, or the prediction of remission or cure. A further relevant category of biomarkers could be those predicting the occurrence of co-morbidities (e.g. memory impairments) or sudden unexpected death. It is important to note that in the discovery of predictive biomarkers, a critical additional challenge is that these biomarkers are stage-dependent. Thus, even in a crosssection of clinically well-defined PWE, the stage of epileptogenesis may differ. This is relevant because the expected proportion of the population being positive for a given biomarker depends on the timing of sampling relative to disease progression. Perhaps more importantly, the roster of biomarkers that predict risk may also vary depending on stage of the epileptogenic process. Some may argue that another kind of biomarkers are the surrogate endpoints, that is, laboratory measurements or physical signs that can be used in therapeutic trials as a substitute for a clinically meaningful endpoint (epileptic seizures) and are expected to predict the effect of the therapy ${ }^{9}$. In our view, however, surrogate endpoints do not strictly fall within the definition of biomarkers and will not be discussed here. 
Why is it so important to identify diagnostic and prognostic biomarkers for epilepsy? Clearly, one major objective in the discovery of diagnostic biomarkers is the individualization of therapy. For prognostic biomarkers, however, an additional crucial goal is the development and appropriate targeting of anti-epileptogenic therapies. The general feasibility of anti-epileptogenic therapies is supported by $>30$ preclinical proof-of-concept studies using animal models of genetic epilepsies, cortical malformations, status epilepticus (SE), or TBI. These studies have either reported favorable anti-epileptogenic (AEG) and/or co-morbidity modifying effects ${ }^{3}$. However, so far none of these experimental studies has led to a clinical anti-epileptogenesis trial. One major reason for this disturbing fact is that the design of appropriately powered clinical trials is not possible when considering even relatively well-defined patient groups. This is due to the heterogeneity of epileptogenesis and post-injury recovery mechanisms. As a consequence, adequately powered clinical AEG trials will only be possible following the identification of biomarkers that allow stratification of patient populations based on the predicted risk of epileptogenesis.

We will critically review the first proof-of-concept preclinical and clinical studies of biomarker discovery in epilepsy. So far, most studies examining the validity of biomarkers, in particular prognostic biomarkers in animal models have relied on animal models with clearly defined initial injury, such as experimental post-status temporal lobe epilepsy (TLE) models, stroke models or TBI models. A large portion of the clinical data has also been obtained from TLE patients. Thus, it is important to bear in mind that most of the biomarker data available reflect a subset of epilepsies, and may not be applicable over the whole spectrum of the epilepsies. We will discuss biomarkers derived from different levels of analysis, ranging from genetic analyses, to parameters derived from circulating markers, to more complex assessments of system function derived from magnetic resonance imaging (MRI), positron emission tomography (PET), or electrophysiological analyses.

\section{Genetic biomarkers}

Genetic mutations can be the cause of epilepsy, make the brain more vulnerable to develop epilepsy after an acquired brain injury such as ischemic stroke or TBI, and also affect the treatment response ${ }^{10,2}$. Genetic markers would have great potential as biomarkers as DNA is readily available 
from patients at-risk admitted to the hospital after epileptogenic injuries like TBI, new-onset SE, or stroke. Several genetic variants have been linked to the modulation of post-injury seizure threshold or to acquired epilepsy (for details see Supplementary Table 1 and references therein). Some of these genes are involved in GABA-ergic neurotransmission such as the GABA-A receptor subunit genes GABRB1 ${ }^{11,12,13}$, GABRB2 ${ }^{14}, \operatorname{GABRB} 3^{15}$, and GABRG2 ${ }^{16,17}$; the glutamic acid decarboxylase 1 gene $\left(G A D 1,{ }^{18}\right)$, and the succinic semialdehyde dehydrogenase gene $\left(A L D H 5 A 1,{ }^{15}\right)$. Susceptibility to TLE has also been associated with polymorphisms in genes involved in serotonergic transmission: serotonin receptor $5-\mathrm{HT}-1 \mathrm{~B}$ and serotonin transporter $5-\mathrm{HTT}{ }^{19,20,21}$. Association of genetic variants with epilepsy was also found for genes involved in regulation of excitability, such as voltage-gated sodium channel $\left(S C N 1{ }^{22}\right)$, the anticonvulsant peptide prodynorphin $\left(P Y D N,{ }^{23}\right)$, methylene tetrahydrofolate reductase $\left(M T H F R,{ }^{24}\right)$ or acid-sensing ion channel $1 \mathrm{~A}\left(A S C / 1 \alpha,{ }^{25}\right)$. Association with epilepsy is not limited to polymorphisms in genes related to neurotransmission and neuronal activity. but has been detected for a number of pro-inflammatory genes including those encoding the CD4O molecule ${ }^{26}, I L-1 B{ }^{27,28}, I L-1 A^{29}$, and the IL-1 receptor antagonist IL-1RA ${ }^{29}$. Another interesting functional group of genes are those potentially involved in protection against oxidative stress: mitochondrial aldehyde dehydrogenase $2(A L D H 2)$, nuclear factor, erythroid 2-like $2\left(N F E 2 L 2,{ }^{30}\right)$, or prion protein $P R N P^{31}$. A possible involvement of glial compartments is highlighted by the association of a SNP in the ATP-sensitive inward rectifier potassium channel 10 (KCNJ10) with seizure susceptibility ${ }^{32}$, as well as the association of TLE with a SNP in KCNJ10 in combination with SNPs in the gene encoding the water channel aquaporin $4\left(A Q P 4,{ }^{33}\right)$. A SNP in the calcium homeostasis modulator $1\left(C A L H M 1,{ }^{34}\right)$ has been suggested to influence TLE susceptibility by controlling cytosolic $\mathrm{Ca}^{2+}$ concentration and/or modulating $A \beta$ levels. Finally, polymorphisms in genes related to cell-cell interactions, like protocadherin $7\left(P C D H 7,{ }^{22}\right)$, neuregulin $1\left(N R G 1,{ }^{35}\right)$, brain-derived neurotrophic factor $\left(B D N F,{ }^{36}\right)$, or key components of the innate immune system and inflammation with a role in neuronal plasticity and excitability, like complement $3^{37}$ have been described.

However, it should be noted that most published association studies of common variants increasing susceptibility to the epilepsies have been small, none have been replicated and they have been limited to candidate polymorphisms or genes. There are not yet any common variants currently in clinical or experimental use as predictors of the development of epilepsy, whether after a brain 
insult or not. More recently, there have been a handful of better-powered genome-wide association studies, suggesting a variety of possible associations in particular populations or epilepsy syndromes (for review see Leu et al., Current Opinion in Neurology, in press, April 2016). A meta-analysis of 8.696

cases and 26.157 controls ${ }^{22}$ ) identified an association between all types of epilepsy and variation in $S C N 1 A$, a gene already robustly linked to a variety of rare or comparatively rare epilepsy syndromes typically featuringfebrile seizures as a component. Even this finding is not yet of proven value in the prediction of risk of epilepsy.

\section{microRNAs}

MicroRNAs (miRNA) are small non-coding RNAs that regulate gene expression at posttranscriptional level ${ }^{38}$. They are differentially expressed in the brain under pathological conditions and may therefore represent both therapeutic targets and diagnostic or prognostic biomarkers for neurological diseases, including epilepsy ${ }^{39,40}$. Several studies have already assessed the potential of miRNAs as biomarkers for different aspects of the epileptogenic process ${ }^{41,42,43}$. Zucchini et al. (2014) ${ }^{44}$ examined the expression of human miRNAs in hippocampal granule cells of surgical specimens available from patients with intractable TLE, and identified 12 miRNAs that were differentially expressed in cases with or without granule cell dispersion. One of these, miR487a, was verified in an extended cohort of patients. Whether miRNA signature of the resected tissue carries a biomarker value for any aspects of the surgical outcome remains to be evaluated.

miRNAs are also found in plasma and serum, associated with proteins or with extracellular vesicles. These circulating miRNAs may represent a new form of intercellular communication, acting as signaling molecules ${ }^{45,46}$. miRNA-containing exosomes can be isolated from brain tissue and potentially cross the blood-brain barrier (BBB), thus providing a possible blood source for biomarker discovery ${ }^{47}$. Importantly, analysis of circulating miRNAs could be a non-invasive approach to be applied at any stage of the disease process. Two recent studies evaluated circulating miRNAs in PWE. Wang et al. $(2015 a)^{48}$ measured serum miRNA levels in 30 PWE and 30 controls, and validated the selected miRNAs in a larger cohort of cases. Six miRNAs were altered in PWE and ROC analysis revealed that miR-106b-5p had the highest sensitivity and specificity for a diagnosis of epilepsy (Table 
1). In another study, Wang et al. (2015b) ${ }^{40}$ evaluated 77 drug-resistant and 81 drug-responsive PWEs as well as 85 healthy controls. Five miRNAs were de-regulated in drug-resistant patients as compared to the other groups (Table 1). Based on ROC analysis, miR-301a-3p had the best diagnostic value for drug-resistant epilepsy. As the authors note, prospective studies are needed to justify the true biomarker value of miRNAs in diagnosis of epilepsy and prediction of drug-refractoriness.

Can circulating miRNAs identify individuals that will develop epilepsy following brain injury? Attempts in this direction have been made in animal models of $\mathrm{SE}^{49,50}$. Ronconet al. (2015) ${ }^{50}$ analyzed miRNAs using micro-arrays in plasma samples collected during the course of epileptogenesis after systemic pilocarpine-induced SE. Levels of 27 miRNAs differed between the control and pilocarpinetreated animals. The miRNAs with altered levels before the appearance of the first epileptic seizure, such miR-9a-3p, represent potential biomarker candidates for epileptogenesis. However, the pilocarpine model is not optimal for biomarker studies as almost all animals will eventually develop epilepsy and the progression of epileptogenesis is fast, occurring within the 1-2 weeks post-SE. Therefore, further studies are needed to confirm the role of miR-9a-3p as a biomarker for epileptogenesis. However, a preliminary ROC analysis indicated that miR-9a-3p was sensitive and specific for SE diagnosis.

Even though the data are promising, a detailed validation of the analysis-related steps will be essential to bring miRNA biomarkers to clinical use. The main concerns relate to establishing standardized sampling (e.g. elimination of platelet contamination), RNA extraction, and miRNA analysis protocols ${ }^{51}$. Until the methodological protocols are harmonized between the laboratories, it will be likely that only strongly altered miRNAs will be suitable as pre-clinical or clinical biomarkers.

\section{Structural biomarkers}

Structural changes are a notable feature of many epilepsies, in particular in chronic temporal lobe epilepsy with Ammon's horn sclerosis, which shows characteristic patterns of damage with segmental neuronal loss, gliosis and axonal reorganization. However, it is still unclear if more subtle forms of structural damage can be detected early on that predict the development of more severe pathology and chronic epilepsy. This issue has been addressed mainly in animal models. T2 magnetic resonance imaging of the amygdala and thalamus has shown promise in the search for biomarkers for 
epileptogenesis in an experimental model of febrile seizures ${ }^{52}$. Another imaging study has linked structural abnormalities in the thalamus and the cortex to increased seizure susceptibility in a model of posttraumatic epilepsy (PTE) induced by lateral fluid-percussion injury ${ }^{53}$. The FEBSTAT study is collecting MRI data on hippocampal changes in children with febrile convulsions ${ }^{54}$. Over the next decade we will learn whether those pathologies, some of which will eventually present as hippocampal sclerosis (e.g, T2 hyperintensity) will predict the development of epilepsy.

Other advanced structural imaging parameters have not yet been tested as biomarkers of epileptogenesis, even though it has been demonstrated that they show significant changes in epileptogenic focal areas in post-injury brain. For example, diffusion tensor imaging (DTI) with high spatial resolution can be used to visualize the progression of structural changes in different hippocampal subfields for months after SE induced by systemic kainic acid or pilocarpine (Fig. 1A-B). Increased fractional anisotropy in the dentate gyrus correlated with mossy fiber sprouting and reorganization of myelinated axons in the inner molecular layer ${ }^{55,56}$. It is likely that DTI and more advanced diffusion MRI techniques such as high angular resolution diffusion imaging (HARDI) (Fig. 1C), will provide even more specific information about microstructural changes in the brain related to cell death, reactive gliosis, and structural axonal plasticity. Furthermore, microstructural imaging techniques probing local magnetic susceptibility differences in the brain, such as phase-imaging and quantitative susceptibility mapping, will aid sensitive detection of microhaemorrhages, calcification, and white matter damage (Fig. 1D) ${ }^{57}$.

\section{Functional and electrophysiological biomarkers}

On a more functional level, electrophysiological parameters have been explored as both diagnostic and predictive biomarkers. In established epilepsy, recurrent seizures constitute the defining disease symptom ${ }^{58}$. An "epileptic seizure" is a transient occurrence of signs and/or symptoms due to abnormal excessive or synchronous neuronal activity in the brain ${ }^{58,59}$. In the context of epileptogenesis, the conceptual question is how networks transform from normal state to become able to generate unprovoked recurrent seizures, and whether there are early excitability signatures that are less conspicuous than seizures. Such signatures could potentially constitute predictive 
biomarkers for epileptogenesis. We will first review the evidence from animal and human work that neuronal excitability biomarkers for the development of epilepsy may exist, and discuss how they might be validated in PWE. Secondly, we will discuss the major technical issue that will determine how well such measures can be used in PWE, namely, the development of noninvasive recording techniques.

Pathological high-frequency oscillations (HFOs). Arguably one of the strongest candidates for a predictive biomarker signature of neuronal hyperexcitability are pathological high-frequency oscillations (HFOs) ${ }^{60,61,62}$. There is currently no uniform definition of pathological HFOs. However, most of the work both in animal models and human epilepsy has focused on brief events in the spectral range of $80-600 \mathrm{~Hz}$, with different appellations being used, depending on the frequency range (i.e. ripples, $80-250 \mathrm{~Hz}$, fast ripples $250-500 \mathrm{~Hz}$ ).

In human chronic epilepsy, HFOs may constitute an important interictal marker of focal epileptogenic zones ${ }^{62}$, and have been clinically used to localize such areas ${ }^{63}$. More importantly, removal of HFO-generating areas led to improved surgical outcomes ${ }^{64,65,66,67}$. Thus, HFOs seem to be reasonably good indicators of the epileptogenic zone. However, studies asking if occurrence of HFOs is predictive of later development of epilepsy have been much scarcer.

In the kainate SE model of epileptogenesis, two different discriminable types of HFOs appear before the onset of generalized seizures, and their occurrence predicted the development of later spontaneous seizures ${ }^{61}$. Region-dependent changes in HFOs have also been observed in the pilocarpine model of epilepsy, with their predictive nature for the severity of the chronic seizure disorder being less clear ${ }^{68}$. In the pilocarpine model of epilepsy, and in humans, HFOs have been analyzed in conjunction with interictal spikes. These studies have yielded a complex temporal and spatial pattern of interictal spikes with and without superimposed HFO patterns ${ }^{69,70}$. Taken together, however, HFOs seem to constitute promising candidates for an excitability-based biomarker for epileptogenesis.

One of the most notable features of virtually all studies examining the relationship of HFOs to the epileptogenic zone has been that these studies were performed using invasive EEG techniques. Without question, these have been extremely useful to delineate the seizure onset zone and to 
validate the application of excitability. However, to provide broadly applicable, clinically useful predictors of the later disease course, non-invasive recording techniques would have to be established. These would have to be capable of precisely measuring the incidence and spectral properties of pathological HFOs, potentially at the cost of anatomical resolution. Studies combining scalp EEG, invasive EEG, and magnetoencephalography (MEG) will be required to validate such noninvasive measures. High-sampling rate magnetoencephalography systems might constitute a promising candidate method to test the validity of HFOs as biomarkers in human epilepsy ${ }^{71,72,73}$. Any high-resolution technology, however, will have substantial problems to overcome. Firstly, the management of large amounts of high-sampling-rate data is challenging. Secondly, criteria for distinguishing HFO signals reliably, and preferentially automatically, have to be developed and validated, a task that is far from trivial ${ }^{74,75}$. A presurgical setting with the opportunity to determine intracranial local field potential signals and MEG signals in parallel may be extremely valuable for this purpose. Finally, the use of HFO biomarkers in conjunction with behavioral state, and/or other EEG markers such as interictal spikes, in a combinatorial fashion may prove to be useful to optimize the predictive efficacy of HFOs ${ }^{75}$. Solving these issues will pave the way to adequately powered clinical studies that repeatedly and noninvasively address cohorts of at-risk patients, and which stand a chance of prospectively addressing the validity of excitability biomarkers.

Future work should seek to determine more precisely (a) what the spectrum of pathological HFOs is in humans, and if they constitute multiple classes of excitability signatures ${ }^{67}$, (b) which of these can be more precisely distinguished from normal high-frequency activity, and (c) develop and validate methods suitable for noninvasive detection of these forms of activity in humans.

Seizure susceptibility. Biomarkers for diagnosis of epileptogenesis would indicate the presence of lowered seizure threshold without the occurrence of seizures. Seizure threshold, which is thought to determine the propensity or likelihood for seizure occurrence is decreased after different types of epileptogenic brain insults in experimental models, including genetic mutation, SE, stroke, or TBI $76,77,78,79,80,81,82$. Interestingly, Löscher and coworkers have recently assessed the seizure threshold repeatedly in different animal models of post-SE TLE during the course of epileptogenesis ${ }^{77,79,82}$. They found some overlap in seizure susceptibility between the animals that developed or did not develop epilepsy, which may have been related to variability in the rate of progression of epileptogenesis 
between the animals within the follow-up time. Interestingly, Brand et al. (2015) ${ }^{82}$ expanded these studies by combining the follow-up of seizure threshold and behavioral alterations during the first 3 weeks after SE. By generating a combinatorial seizure threshold/behavioral score biomarker they were able to predict epileptogenesis with high sensitivity and specificity (Fig. 2A, ${ }^{83}$ ). Whether these data can be generalized to models of PTE and post-stroke epilepsy (PSE), and eventually to humans, remains to be explored.

In patients evaluated for epilepsy surgery, the area of ictogenic focus shows a lower threshold for induced electrographic epileptiform or imaging changes after administration of convulsants (pentylenetetrazol, bicuculline) or electrical stimulation via depth electrodes. These observations provide some support for the concept of using seizure susceptibility testing in pre-clinical models to diagnose epileptogenesis ${ }^{84,85,86,87}$, even though electrical stimulation was shown to be of limited utility in determining focus lateralization ${ }^{87}$.

Metabolic and neurotransmitter-related biomarkers. In addition to electrophysiological measurements of function, imaging modalities can report on the functional state of brain tissue by assessing metabolic parameters noninvasively. On the preclinical level, a longitudinal analysis by proton magnetic resonance spectroscopy $\left({ }^{1} \mathrm{H}-\mathrm{MRS}\right)$ in the hippocampus of rats exposed to SE showed a progressive increase in myo-inositol $(\mathrm{mln})$ and glutathione (GSH) levels before the rats developed spontaneous seizures ${ }^{88}$. Notably, a negative correlation was found between the levels of these metabolites during epileptogenesis and the extent of neurodegeneration in chronic epileptic rats. Moreover, GSH levels during epileptogenesis showed a negative correlation with the frequency of spontaneous seizures. ROC analyses showed that the levels of these two metabolites during epileptogenesis are very good discriminators for differentiating control rats from animals that will develop epilepsy (Fig. 2B, C).

${ }^{18}$ F-fluoro-2-desoxy-D-glucose ( $\left.\left[{ }^{18} \mathrm{~F}\right] \mathrm{FDG}\right)$ PET has been used in two preclinical studies to evaluate the association between glucose metabolism and epileptogenesis after TBI or SE ${ }^{89,90}$. Both studies showed abnormalities in $\left[{ }^{18} \mathrm{~F}\right]$ FDG PET during epileptogenesis, but the sensitivity and specificity of the changes remain to be explored. Furthermore, radioisotope imaging studies have 
assessed $\mathrm{GABA}_{A}$ or NMDA receptors ${ }^{91,92}$. However, the potential of receptor labeling studies as epileptogenesis biomarkers still remains to be demonstrated.

Finally, large scale network alterations have gained momentum as a key concept in epilepsy, mainly due to advances of non-invasive imaging techniques which provide maps of functional and structural connectivity in the brain by exploiting resting state $\mathrm{FMRI}$ and diffusion MRI based tractography. While there is strong evidence of functional connectivity changes in PWE, there are almost no studies addressing connectivity changes during epileptogenesis, before the appearance of the first unprovoked seizure. In a recent preclinical study, resting state connectivity was measured in rats 4 months after lateral fluid percussion-induced TBI and compared with hyperexcitability of the brain assessed by the pentylenetetrazol seizure-susceptibility test. However, no significant correlation between functional connectivity and seizure susceptibility was found, perhaps due to the small number of animals in the study ${ }^{81}$. Nevertheless, it is possible that adequately powered network analysis in animal models can produce clinically testable hypotheses in the search for biomarkers.

\section{Biomarkers of epilepsy-related neuroinflammation}

In addition to electrophysiological biomarkers that directly report on neuronal function, it has been shown that neuroinflammation is a prominent feature of most types of epilepsies. Neuroinflammation is determined by the synthesis and release of cytokines, danger signals, chemokines, and down-stream effector molecules, by microglia, astrocytes, neurons and the microvessel endothelium, in the context of innate immunity activation ${ }^{93}$. Clinical evidence shows that neuroinflammation is a hallmark of the epileptic focus in pharmacoresistant epilepsies. Moreover, neuroinflammatory mechanisms contribute to seizure generation in experimental epilepsy models (ictogenesis) ${ }^{94,95}$. There is also evidence of rapid onset and persistent neuroinflammation during epileptogenesis in rodents ${ }^{96}$. These findings, together with evidence of disease-modifications mediated by drugs targeting the inflammatory cascade ${ }^{97,98}$, suggest that neuroinflammation plays a role in disease development. Even though it will be critical to separate the changes in inflammatory markers which relate to injury itself from those that indicate the development of epilepsy, 
neuroinflammation is not only a promising target for novel therapies but also a potential mechanistic biomarker of epileptogenesis and ictogenesis.

Molecular brain imaging techniques targeting inflammatory cells and molecules as well as blood measurements of inflammatory mediators hold promise for monitoring neuroinflammation ${ }^{99}$ in human epilepsy. Imaging techniques with high translational potential include PET and MRI ${ }^{100,99}$ (see Fig. 3A for imaging of microglial activation with TSPO ligands). A recent preclinical study made an attempt to validate an imaging biomarker of epileptogenesis in a rat model of prolonged febrile seizures (FS), in which only a subpopulation of animals developed epilepsy ${ }^{52}$. ROC analysis showed that a decrease in amygdaloid and medial thalamic T2 relaxation times measured at $2 \mathrm{~h}$ post-FS predicted post-FS epileptogenesis (Table 1). Notably, the reduction was correlated with enhanced oxygen utilization, increase in venous blood deoxyhemoglobin, and release of the neuroinflammatory (ictogenic) protein, high-mobility group protein 1 (HMGB1), from amygdaloid neurons ${ }^{94}$. HMGB1 is bound to nuclei and its cellular release requires a nucleus-to-cytosol translocation, which is a highly energy-demanding process. Moreover, the temporal evolution of HMGB1 translocation during epileptogenesis was congruent with the changes in T2 signal. The early decrease in T2 signal in the amygdala and the dorsal hippocampus was found to correlate also with the learning disabilities that some rats developed 2-3 months after FS, even though the sensitivity and specificity of T2 as biomarker for cognitive decline were not assessed ${ }^{101}$.

Up to now, there is only one proof-of-concept clinical study showing that brain imaging can detect neuroinflammation in human epilepsy. PET ligand of a 18 kDa-translocator protein (TSPO), a protein mostly induced in activated microglia and astrocytes, was shown to indicate the region of seizure origin and generalization in patients with pharmacoresistant focal onset epilepsy ${ }^{102}$. Further studies will show whether TSPO-PET, other PET ligands, or MRI tools designed for detecting neuroinflammation can be used to stratify injured patients with high risk of developing epilepsy, surgical candidates, or patients who will benefit from anti-inflammatory therapies ${ }^{88}$.

The search for blood biomarkers of neuroinflammation relies upon the identification of molecules that are relatively stable in biological fluids and can be rapidly measured in an affordable way. The short blood half-life of some neuroinflammatory molecules implicated in epilepsy, such as 
IL-1 $\beta$ has hampered investigations of their biomarker value, and produced discordant results ${ }^{94}$. The circulating molecules mirroring neuroinflammation may originate by CSF-to-blood diffusion or derive from activated peripheral leukocytes. Ideally, the inflammatory molecules measurable in blood should be CNS-specific and their analysis should not be confounded by non-specific release from peripheral sources (e.g., complement factors released by liver). A recent proof-of-principle study assessed plasma concentrations of an intercellular adhesion molecule of strictly CNS origin, namely soluble sICAM5, also known as telencephalin ${ }^{103}$ (Table 1). This molecule is specifically expressed by glutamatergic neurons and plays an active role in synapse formation and dendritic spine plasticity. Additionally, it has anti-inflammatory properties in microglia and lymphocytes. sICAM5, together with an array of inflammatory mediators, was measured in blood samples from people with drug-resistant focal epilepsy during the interictal phase, disregarding timing of the last seizure, and compared with healthy controls. A 5-fold reduction of sICAM5 was detected in patients, together with a significant increment in various pro-inflammatory cytokines, the highest of which was the pro-ictogenic cytokine IL-1 ${ }^{94}$. Pollard et al. (2012) ${ }^{103}$ showed that none of the tested analytes discriminated perfectly between PWE and controls. However, the ROC analysis indicated AUC1.0 when the plasma ratio between the chemokine TARC (CCL17) and sICAM5 was used as biomarker.Together with TSPO-PET imaging, these data support the idea that markers of neuroinflammatory changes can serve as biomarkers for different aspects of the epileptogenic process.

Validation of inflammatory and other markers to predict the outcomes of the epileptogenic process after different genetic abnormalities or brain injuries requires prospective studies in larger cohorts of well-phenotyped patients with diverse etiology for epilepsy. Three ongoing studies: FEBSTAT ${ }^{104}$, SANAD II (http://www.sanad2.org.uk/) and HEP (http://humanepilepsyproject.org/)may soon provide valuable information in this context.

\section{Epilepsy biomarkers derived from brain microvascular injury}

Another functional system that is intimately interlinked with neuronal function, and is altered in many forms of epilepsy is the brain microvascular system. Microvascular injury can mediate delayed and long-lasting functional and structural changes within the local neurovascular network (Fig. 3B-D). 
Specifically, BBB dysfunction, and the associated leakage of serum proteins (e.g., albumin) after epileptogenic insults initiate glial activation and inflammatory response - hallmark pathologies of the epileptogenic brain. In brief, serum albumin activates specific signaling pathways in astrocytes, leading to a transcriptional response mediating reduction in buffering of extracellular $\mathrm{K}^{+}$and glutamate, and upsurge of local neuroinflammatory responses, as well as selective excitatory synaptogenesis $^{105,106}$. These astrocyte-mediated responses lead to hyperexcitability and hyperconnectivity within the neuronal network.

Microvasculopathy and BBB failure are prominent features of multiple animal models of epilepsy induced by TBI, stroke, or SE. Animal studies indicate that the presence of microvascular injury indicates brain regions undergoing vascular-mediated epileptogenesis. In humans with TBI or stroke, MRI studies consistently identify microvascular pathology, and these findings have been confirmed neuropathologically ${ }^{107}$. An analysis of resected epileptic tissue from patients with pharmacoresistant epilepsy also frequently reveals vascular damage and leakage of serum albumin into the neuropil ${ }^{108,109,110}$. Moreover, cerebrovascular dysfunction correlates well with co-morbidities, such as behavioral and cognitive deficits ${ }^{111}$. Finally, established neuroimaging methods enable quantitative measurement of microvascular functional integrity including BBB permeability, cerebral blood flow (CBF), cerebral blood volume (CBV), angiogenesis, and cerebrovascular reactivity (CVR) in animals and humans ${ }^{112,113}$. The availability of new imaging tools underscores the potential of microvasculopathy-linked biomarkers for post-injury epileptogenesis.

Currently, however, there are no prospective studies testing the predictive value of microvascular dysfunction either in animal models or in the clinical setting. The retrospective study of Tomkins and colleagues $(2008)^{114}$ used contrast-enhanced MRI and quantitative EEG analysis in 37 patients following mild-moderate TBI, of whom 19 had PTE while 18 suffered from post-traumatic headache and non-specific complaints. Interestingly, all TBI patients showed some EEG slowing compared to controls (higher delta and theta, and lower alpha), and no differences were found between patients with or without PTE. In contrast, people with PTE were more likely to demonstrate BBB lesion when compared to those without PTE. Moreover, in most of the patients with PTE, the BBB lesion was co-localized with the suspected epileptic region (ROC analysis resulted in AUC of 0.85 , $p<0.05$, Fig. 3D). Interestingly, the volume of brain tissue with abnormal permeability was on the 
average 6-fold higher in patients with than without PTE, suggesting that test sensitivity and specificity had been higher if a volume threshold had been applied. While this study confirmed that quantifying vascular permeability is feasible in TBI patients, it is limited by the small number of patients and selection bias. Therefore, the study did not allow to draw the conclusion that vascular functions can predict epilepsy - or in other words, serve as a biomarker for epileptogenesis. On the positive side, several reports show that BBB dysfunction is co-localized to the site of the epileptic network ${ }^{115,116}$, further supporting the notion that microvasculopathy may indeed mirror one relevant aspect of the epileptogenic network.

\section{Current challenges in identification of biomarkers for epilepsy}

As is clear from the above, the past ten years have led to some promising developments in the biomarker field, but have also served to highlight key challenges in the design of epilepsy biomarker strategies.

Key challenges related to animal models. Animal models, in particular those in which an initial injury causes epilepsy, have been successfully used to identify and validate biomarkers in the preclinical setting. However, while stroke and TBI models might be expected to closely parallel the etiology of the human subject, this is certainly not the case for all models. Post-status models, for instance, closely phenocopy TLE with Ammon's horn sclerosis, but it is not clear at all in how far they copy processes of epileptogenesis in human TLE. Likewise, research into biomarkers has so far mainly focused on the abovementioned models. It is not clear so far which biomarkers are generally applicable across models, and which are model-specific.

A further challenge in post-SE models is the fraction of animals that ultimately develop chronic epilepsy. In rodent models of PSE or PTE, only a subpopulation of animals develops epilepsy. In SE models, which are the most commonly used models of epileptogenesis, however, almost all animals develop epilepsy under the current modeling paradigms. This is problematic in biomarker studies as it is difficult to generate a sufficient number of animals to be stratified into the two populations of injured animals, namely those that will develop epilepsy and those that will not ${ }^{117,118,119}$. Recent 
efforts to refine SE models suggest viable alternatives. By using a drug-cocktail that irreversibly terminates pilocarpine-induced SE at60, 90, or 120 min post-SE, Brandt and colleagues (2015) ${ }^{82}$ were able to modify the outcome in such a way that only a subpopulation of animals with SE developed epilepsy. Similar findings have been previously obtained by terminating chemically or electricallyinduced SE with diazepam ${ }^{120,121}$ or by using younger animals ${ }^{122}$. Another dimension of model development is the search for biomarkers that in high-throughput in vitro models would predict the efficacy of novel anti-epileptogenic treatments in in vivo models and even in human epilepsy ${ }^{123}$. Exploring multiple species may also help to link animal and human studies by exploring shared genetic susceptibility factors between humans and other species.

Key challenges related to the heterogeneity of the epilepsies. The heterogeneity of epilepsies and epileptic syndromes has been alluded to above. Clearly, genetic individual heterogeneity, ethnicity, and gender may have large influences on biomarker expression. Moreover, effects of medication or co-morbidities on biomarker profiles cannot be excluded. One further important source of variability is the age of patients. So far, studies have focused on biomarker identification in adults. However, the onset of epilepsy is often in childhood, which will need to be taken into account in epilepsy biomarker studies in the future. . Large-scale and deeper genetic association studies (for example using next-generation sequencing data) may point to mechanisms shared across different types of epilepsy and may help predict risk after brain insult. Such studies are currently under way.

Key challenges related to accessibility of biomarkers. While basic research has identified multiple potential biomarkers, translation requires these biomarkers to be accessible to physicians. This relates to the accessibility of specimens to be analyzed, with brain tissue being accessible only from a very limited patient population a long way into the disease history, but blood, biological fluids or - to a lesser extent - CSF are much more readily available. It will be crucial to determine how useful biomarkers measured from accessible specimens are. Moreover, it will be important to validate technologies to assess brain function noninvasively (i.e. MEG or functional imaging techniques). In this context, the cost of biomarker analyses will be a factor in the future broad application.

Key challenges related to identification of biomarker patterns. An underestimated challenge in the evaluation of biomarkers is the development of biomathematical analysis strategies for the 
complex datasets that are increasingly available from PWE. These may include many of the categories of data mentioned above. There will be a high demand on resources for mathematical modeling and pattern-mining, as well as the development of novel analysis tools to define patterns of relevant biomarkers from large datasets.

\section{The way forward towards multimodal epilepsy biomarker platforms}

What, then, is the way forward? Valuable lessons can be learned from other fields. Probably the field most advanced in terms of biomarker discovery and their clinical use is oncology. This field has been driven both by technological advances in -omics technologies which allow to dissect out molecular disease-relevant pathways, and by the wide availability of tumor tissue following resective surgery. As a consequence, molecular platforms for therapy stratification of people with glioma are already a clinical reality ${ }^{124}$. From the lessons learned in the oncology field, and the key challenges we have identified, we suggest that the following avenues should be focused upon in the future.

Validate animal models. Epilepsy is one of the rare neurological conditions, in which living human tissue is available for validation of biomarker expression in the focal area, most often at the end stage of the disease. Moreover, epilepsy is blessed with access to a large variety of animal models which have led to a successful development of anti-seizure therapies. Still, many of the clinically prevalent epilepsy syndromes have none or only a limited number of incompletely validated animal models (e.g., post-stroke epilepsy, cortical dysplasia, pediatric epilepsies). Development of animal models with a high face validity requires accurate phenotyping of a given human epilepsy syndrome which can be used in a model design. Examples in this direction are the large studies on TBI in Europe and USA (TRACK-TBI, CENTER-TBI) which will provide such information.

Establish multimodal biomarker panels. Experiences in the oncology field have shown the value of combining biomarkers to achieve higher clinical utility. This has several reasons. Firstly, the pathologies are diverse, and assessing a panel of biomarkers that signal different pathogenic mechanisms progressing in parallel at any given timepoint may allow a clearer separation of different disease entities. Secondly, multimodal markers may offer an opportunity for staging the disease progression. Thirdly, multimodal markers may offer the chance to better delineate biomarker combinations for specific co-morbidities (Fig. 4). Thus, we suggest that combinatorial, etiology- 
dependent approaches will be needed both to be sensitive to a given type of epilepsy and to stage the evolution of the disease in that condition.

Implement collaborative research approaches. Addressing the heterogeneity of human epilepsies, and developing and analyzing syndrome-specific animal models is a huge task that requires collaborative efforts. A start has been made with several large consortia that have a chance to implement appropriately powered analyses in multiple animal models and large patient groups.

Improving sensitivity of analysis platforms. In addition to model refinement, there is a major need for increasing the sensitivity of analysis platforms. Progress in automated detection of various soluble biomarkers in body fluids, simultaneous pattern recognition of molecular combinations, and multiplexed analysis of single cell surface and intracellular macromolecules with next generation flowcytometry techniques will undoubtedly advance biomarker identification, not only in patient samples but also in pre-clinical studies. In fact, animal studies provide only small amounts of blood, CSF, saliva, eye secretion, microbiota, or urine samples for analysis, which is a factor to be considered when designing preclinical biomarker studies. High field clinical MRI $(\geq 3 T)$ with advanced parallel imaging is already commonly available making translation of findings from preclinical MRI to clinical settings feasible. Technical improvements in gradient hardware and pulse sequences will aid more precise and fast mapping of brain networks.

Improved biomathematical approaches. The availability of datasets from high-throughput technologies, as well as increasingly complex clinicopathological datasets bears great potential for identification of biomarkers. However, there are significant biomathematical challenges in evaluating these complex, multidimensional datasets, and identifying combinatorial biomarker signatures. We predict that it will be necessary to further develop systems biology approaches that incorporate datadriven evaluation of complex datasets, but also integrate expert knowledge about the relevant underlying biological function ${ }^{125}$.

\section{Validation and translation of biomarkers to therapies}


The key final goal of biomarker identification is the validation of candidate biomarkers in larger prospective preclinical and clinical studies across different cohorts and underlying pathologies ${ }^{126,127,128,129,130}$. So far, study cohorts have been relatively small, challenging the statistical power of the analyses. In addition, phenotyping of epilepsy and co-morbidities has been limited. Finally, validation cohorts for candidate biomarkers have been used only by two studies ${ }^{40,48}$. An additional challenge that will need to be faced is the current lack of standardized preclinical and clinical study designs for epilepsy biomarker search. However, novel, multistage adaptive clinical study designs are being developed for other indications ${ }^{131}$.

A cornerstone of any validation of biomarkers will be the recruitment of large numbers of patients with careful clinicopathological evaluation. This problem has been recognized, and common data elements (CDEs) for harmonization of studies on epilepsy between centers are already available for clinical studies (https://commondataelements.ninds.nih.gov/). The first CDEs specifically designed for harmonization of biomarker and proof-of-concept preclinical studies among laboratories have just become available (EPITARGET web site: www.epitarget.eu). The work ongoing in the ILAE and AES/NINDS translational task force for harmonization of preclinical methodologies will extend the EPITARGET CDEs to a wider spectrum of models and methodologies. The coming ten years will show if these and related efforts will form a basis for coherent collection of genetic, pathological, functional, and behavioral epilepsy phenotypes that can be leveraged into successful clinical studies, and that in turn can feed back onto model development and preclinical biomarker identification.

\section{Conclusions}

The development of biomarkers in epilepsy, especially those capable of reliably predicting clinically-significant epileptogenesis, would be of huge value for creating the essential background for testing anti-epileptogenic therapies in humans. Whatever final common pathways might be shared across the human epilepsies in the clinical manifestation of seizures, the process of getting to those final common pathways, that is, the processes of epileptogenesis are likely to be causation- and disease-specific. As our knowledge increases, especially from genetics, on how disparate the conditions that constitute 'epilepsy' in humans are, we will need to consider how biomarkers will best reveal such diversity. Considering the cost and the efforts of developing disease-specific biomarkers 
for each individual epilepsy, data from animal models will be crucial in ensuring that properlydesigned, adequately-powered clinical validation studies can be produced. Combinatorial platforms would seem most likely to be successful in this context. Although the challenges ahead should not be underestimated, they should not preclude continuous research in the field since biomarker discovery would be a major advance in the management of epilepsy in humans. Biomarker discovery could be considered to be an advance in personalized medicine to the point of prevention in the right person at the right time, not just symptomatic treatment.

The promising proof-of-concept data on putative epilepsy biomarkers summarized in Table $\mathbf{3}$ will undoubtedly motivate the design of adequately powered preclinical and clinical studies to maximize the accuracy and predictability of the biomarkers assessed. Further, inclusion of biomarker sample collection and analysis into ongoing and planned preclinical and clinical treatment trials will open the possibility for prediction of treatment efficacy. These tasks require regulatory standards for biomarker development and use. The final test will be to compare the biomarker platforms between the clinical study cohorts and corresponding animal models, which has not been vigorously done as yet in any of the brain diseases. In this regard, the epilepsy field with a large variety of animal models to assay the human epilepsy syndromes provides an unique opportunity to evaluate preclinical biomarkers in clinical setting and vice versa. 
Table 1. Epilepsy biomarkers. So far, predictive or diagnostic biomarkers have been discovered for epileptogenesis, epilepsy diagnosis, severity of epilepsy, and epileptogenicity. Abbreviations: DTI, diffusion tensor imaging; iEC, intracortical (entorhinal cortex); EEG,

electroencephalogram; FA, fractional anisotropy; $\mathrm{HC}$, intrahippocampal; HFO, high-frequency oscillation; MRI, magnetic resonance imaging; mTLE, medial temporal lobe epilepsy; P11, postnatal day 11; SE, status epilepticus; sICAM5, telencephalin; TARC, thymus and activation regulated chemokine (CCL17); T2, a time constant for the decay of transverse magnetization.

\begin{tabular}{|c|c|c|c|c|}
\hline Biomarker type and indication & Tissue & Modality & Biomarker & Reference \\
\hline Diagnostic biomarker for epilepsy & Serum & Molecular analysis & increased level of miR-106b-5p & 48 \\
\hline Diagnostic biomarker for focal epilepsy & Plasma & Molecular analysis & increased TARC/sICAM5 ratio & 103 \\
\hline $\begin{array}{l}\text { Diagnostic biomarker for drug-refractory } \\
\text { epilepsy }\end{array}$ & Serum & Molecular analysis & decreased level of miR-301a-3p & 40 \\
\hline $\begin{array}{l}\text { Prognostic biomarker for epileptogenesis after } \\
\text { hyperthermia-induced SE in P11 rats }\end{array}$ & Brain & $\mathrm{MRI}$ & Reduced amygdalaT2 & 52 \\
\hline Diagnostic biomarker for drug-refractory mTLE & Brain & $\mathrm{MRI}$ & $\begin{array}{l}\text { reduced temporal lobe white } \\
\text { matter FA in DTI }\end{array}$ & 132 \\
\hline $\begin{array}{l}\text { Diagnostic biomarker for localization of seizure } \\
\text { onset zone (tissue epileptogenicity) }\end{array}$ & Brain & $\begin{array}{l}\text { iHC or iECEEG } \\
\text { scalp EEG }\end{array}$ & occurrence of HFOs & $\begin{array}{l}62 \\
63\end{array}$ \\
\hline
\end{tabular}


Supplementary Table 1. Comprehensive list of genes with allelic variants related to the increased susceptibility to develop epilepsy after acquired brain insults. The gene list was generated based on PubMed search in November 2015. Abbreviations: VNTR: variable number tandem repeats, DNP: Dinucleotide polymorphism, TBI: traumatic brain injury, PTS: Posttraumatic seizures, TLE: Temporal lobe epilepsy. MTLE-FS+: Mesial temporal lobe epilepsy with febrile seizures plus.

\begin{tabular}{|c|c|c|}
\hline Gene & $\begin{array}{l}\text { SNP or poly- } \\
\text { morphism }\end{array}$ & Function \& Relevance \\
\hline \multicolumn{3}{|r|}{ Post-traumatic epilepsy } \\
\hline $\begin{array}{l}\text { ADORA1, } \\
\text { adenosine A1 } \\
\text { receptor }\end{array}$ & $\begin{array}{l}\text { rs3766553 } \\
\text { rs10920573 }\end{array}$ & $\begin{array}{l}\text { Inhibitory neuromodulation, antiseizure properties; rs3766553 } \\
\text { associated with latency to PTS, rs } 10920573 \text { associated with late PTS } \\
\text { occurrence }{ }^{133} \text {. }\end{array}$ \\
\hline $\begin{array}{l}A P O E, \\
\text { apolipoprotein } E\end{array}$ & $\varepsilon 4$ status & $\begin{array}{l}\text { Binding, internalization, and catabolism of lipoprotein particles; } \varepsilon 4 \\
\text { allele increases risk of posttraumatic seizures following } \mathrm{TB}^{134} \text {. }\end{array}$ \\
\hline $\begin{array}{l}\text { GAD1, glutamic } \\
\text { acid } \\
\text { decarboxylase }\end{array}$ & $\begin{array}{l}\text { rs3828275 } \\
\text { rs769391 } \\
\text { rs3791878 }\end{array}$ & $\begin{array}{l}\text { Inhibitory neurotransmission, enzyme catalyzing of GABA production } \\
\text { from L-glutamic acid; rs3828275 associated with risk of early ( }<1 \mathrm{wk}) \\
\text { PTS after TBI; rs } 769391 \text { and rs3791878 associated with risk of PTS }>1 \\
\text { wk }-6 \text { mo post TBI }\end{array}$ \\
\hline $\begin{array}{l}\text { IL-16, interleukin } \\
16\end{array}$ & rs1143634 & $\begin{array}{l}\text { Proinflammatory cytokine; CT genotype associated with decreased } \\
\text { serum } I L-16 \text { levels, higher IL-1 } \beta \text { CSF/serum ratios, and increased risk of } \\
\text { PTE after TBI }{ }^{135} \text {. }\end{array}$ \\
\hline $\begin{array}{l}\text { MTHFR, } \\
\text { methylene- } \\
\text { tetrahydrofolate } \\
\text { reductase }\end{array}$ & rs1801133 & $\begin{array}{l}\text { TT genotype is linked to increased plasma/serum levels of pro- } \\
\text { convulsive homocysteine; predisposes for epilepsy following TBI in } \\
\text { military personnel }{ }^{24} \text {. }\end{array}$ \\
\hline \multicolumn{3}{|r|}{ Post-stroke epilepsy } \\
\hline $\begin{array}{l}\text { CD40, CD40 } \\
\text { molecule, } T N F \\
\text { receptor } \\
\text { superfamily } 5\end{array}$ & rs1883832 & $\begin{array}{l}\text { Proinflammatory action; T allele associated with increased SCD4OL } \\
\text { plasma levels, CD40 mRNA expression in peripheral blood mononuclear } \\
\text { cells and with increased PSE susceptibility. }{ }^{26} \text {. }\end{array}$ \\
\hline $\begin{array}{l}\text { ALDH2, } \\
\text { mitochondrial } \\
\text { aldehyde } \\
\text { dehydrogenase } 2\end{array}$ & rs671 & $\begin{array}{l}\text { Alcohol metabolism, protects against oxidative stress; A allele } \\
\text { associated with higher plasma levels of oxidative stress marker 4- } \\
\text { hydroxy-2-nonenal (4-HNE), and more frequent in PSE patients. }{ }^{136} .\end{array}$ \\
\hline \multicolumn{3}{|r|}{ Other (etiology non-specified) } \\
\hline $\begin{array}{l}\text { AQP4, aquaporin } \\
4\end{array}$ & $\begin{array}{l}\text { ss119336753 } \\
\text { ss119336753 } \\
\text { rs1058424 }\end{array}$ & $\begin{array}{l}\text { Glial water channel; Combination of three SNPs in AQP4 together with } \\
\text { two SNPs in the KCNJ10 gene associated with TLE }{ }^{33} \text {. }\end{array}$ \\
\hline $\begin{array}{l}\text { ALDH5A1, } \\
\text { aldehyde } \\
\text { dehydrogenase } 5 \\
\text { family, member } \\
\text { A1 }\end{array}$ & rs1883415 & $\begin{array}{l}\text { Metabolism of GABA; C allele influencing Egr-3 binding to ALDH5A1 } \\
\text { promoter and resulting in higher ALDH5A1 mRNA expression is more } \\
\text { frequent in TLE patients }{ }^{15} \text {. }\end{array}$ \\
\hline
\end{tabular}




\begin{tabular}{|c|c|c|}
\hline $\begin{array}{l}\text { ASIC1a, acid- } \\
\text { sensing ion } \\
\text { channel 1a }\end{array}$ & rs844347 & $\begin{array}{l}\text { Ligand-gated cation channel activated by extracellular } \mathrm{H}^{+} \text {enhancing } \\
\text { neuronal excitability; A allele more frequent in TLE patients }\end{array}$ \\
\hline $\begin{array}{l}\text { BDNF, brain- } \\
\text { derived neuro- } \\
\text { trophic factor }\end{array}$ & Rs6265 & Neurotrophin; Met66 allele frequency lower in TLE ${ }^{36}$ \\
\hline $\begin{array}{l}\text { CALHM1, } \mathrm{Ca}^{2+} \\
\text { homeostasis } \\
\text { modulator } 1\end{array}$ & rs11191692 & $\begin{array}{l}\mathrm{Ca}^{2+} \text { channel involved in } \mathrm{Ca}^{2+} \text { homeostasis and processing of APP; A } \\
\text { allele frequency increased in TLE patients }{ }^{34} \text {. }\end{array}$ \\
\hline $\begin{array}{l}\text { CAMSAP1L1, } \\
\text { calmodulin } \\
\text { regulated } \\
\text { spectrin- } \\
\text { associated } \\
\text { protein family } 2\end{array}$ & rs6660197 & $\begin{array}{l}\text { Cytoskeletal protein regulating organization of cellular organelles; } \\
\text { associated with susceptibility to epilepsy in Chinese population }{ }^{137} \text {. }\end{array}$ \\
\hline $\begin{array}{l}\text { C3, complement } \\
\text { complement } \mathrm{C} 3\end{array}$ & $\begin{array}{l}\text { DNP: } \\
\text { GF100472 }\end{array}$ & $\begin{array}{l}\text { Complement activation, participates in synapse elimination during } \\
\text { development and adult neurogenesis, increased expression in TLE; } \\
\text { associated with susceptibility to MTLE-FS }+{ }^{37} \text {. }\end{array}$ \\
\hline $\begin{array}{l}\text { GABRB1, } \\
\text { GABA } A_{A} \text { receptor, } \\
\text { Beta } 1\end{array}$ & G1465A & $\begin{array}{l}\mathrm{GABA}_{A} \text { receptor subunit; associated with TLE, A-allele increases risk of } \\
\mathrm{mTLE} \mathrm{F}^{13,11,12} \text {. }\end{array}$ \\
\hline $\begin{array}{l}\text { GABRB2, } \\
\text { GABA } A_{A} \text { receptor, } \\
\text { Beta } 2\end{array}$ & rs967932 & $\mathrm{GABA}_{A}$ receptor subunit; $A$ allele increases risk of $m \mathrm{TLE}^{14}$. \\
\hline $\begin{array}{l}\text { GABRB3, } \\
\text { GABA } A_{A} \text { receptor, } \\
\text { Beta } 3\end{array}$ & rs4906902 & $\begin{array}{l}\text { GABA }_{A} \text { receptor subunit; } G \text { allele influencing MEF-2 binding to GABARB3 } \\
\text { promoter overrepresented in mTLE patients with depression }{ }^{15} \text {. }\end{array}$ \\
\hline $\begin{array}{l}\text { GABRG2, GABA } \\
\text { receptor, Gamma } \\
2\end{array}$ & $\begin{array}{l}\text { rs211037 } \\
\text { rs210987 }\end{array}$ & $\begin{array}{l}\text { GABA }_{A} \text { receptor subunit; rs211037 associated with occurrence of } \\
\text { symptomatic epilepsy and partial seizures and rs } 210987 \text { associated with } \\
\text { symptomatic epilepsy in Chinese population }{ }^{16,17} \text {. }\end{array}$ \\
\hline $\begin{array}{l}\text { 5-HTT, serotonin } \\
\text { transporter }\end{array}$ & $\begin{array}{l}\text { VNTR in 2nd } \\
\text { intron }\end{array}$ & $\begin{array}{l}\text { Serotonin transporter; association of frequency of the } 10 \text { repeat in TLE } \\
\text { patients (conflicting results) }{ }^{20,21} \text {. }\end{array}$ \\
\hline $\begin{array}{l}5-H T-1 B, \\
\text { serotonin } \\
\text { receptor } 1 B\end{array}$ & rs6296 & Serotonin receptor; G allele overrepresented in TLE patients ${ }^{19}$. \\
\hline SESN3, sestrin 3 & rs10501829 & $\begin{array}{l}\text { Stress responsive protein; rs10501829 in the vicinity of SESN3. SESN3 } \\
\text { expression correlates with transcription module relevant for } \operatorname{TLE}^{138} . .\end{array}$ \\
\hline $\begin{array}{l}\text { IL1A (IL- } \\
1 \alpha) \text {,interleukin } \\
1 \alpha\end{array}$ & rs1800587 & $\begin{array}{l}\text { Proinflammatory cytokine; associated with hippocampal sclerosis in TLE } \\
\text { patients }^{29} \text {. }\end{array}$ \\
\hline $\begin{array}{l}\text { IL1B (IL-1B), } \\
\text { interleukin } 1 \beta\end{array}$ & rs16944 & $\begin{array}{l}\text { Proinflammatory cytokine; associated with hippocampal sclerosis in TLE } \\
\text { patients }{ }^{28,27} \text {. }\end{array}$ \\
\hline $\begin{array}{l}\text { II-1RA, II-1 } \\
\text { receptoragonist }\end{array}$ & $\begin{array}{l}\text { VNTR in exon } \\
2\end{array}$ & Differences between controls and TLE-HS- patients ${ }^{29}$. \\
\hline $\begin{array}{l}\text { KCNJ10 (Kir4.1), } \\
\text { inwardly } \\
\text { rectifying } K^{+}\end{array}$ & rs1130183 & $\begin{array}{l}\text { ATP-sensitive inward rectifier } \mathrm{K}^{+} \text {channel } 10 \text {; missense variation in } \\
\text { KCNJ10 or a variation in close vicinity is related to general seizure } \\
\text { susceptibility }{ }^{32} \text {. }\end{array}$ \\
\hline
\end{tabular}




\begin{tabular}{|c|c|c|}
\hline channel & & \\
\hline $\begin{array}{l}\text { NRG1, neuregulin } \\
1\end{array}$ & rs35753505 & $\begin{array}{l}\text { Membrane glycoprotein mediating cell-cell signaling; associated with } \\
\text { TLE in males }{ }^{35} \text {. }\end{array}$ \\
\hline $\begin{array}{l}\text { NFE2L2, Nuclear } \\
\text { Factor, Erythroid } \\
\text { 2-Like 2 (Nrf2) }\end{array}$ & $\begin{array}{l}\text { rs7557529- } \\
\text { rs35652124- } \\
\text { rs6706649- } \\
\text { rs6721961- } \\
\text { rs2886161- } \\
\text { rs1806649- } \\
\text { rs2001350- } \\
\text { rs10183914- } \\
\text { rs2706110 }\end{array}$ & $\begin{array}{l}\text { Transcription factor regulating the expression of many genes in } \\
\text { antioxidant pathway; the haplotype AAGC AGAGG was associated with } \\
\text { an increased risk of } \operatorname{TLE}^{30} \text {. }\end{array}$ \\
\hline $\begin{array}{l}\text { PRNP, prion } \\
\text { protein }\end{array}$ & rs1799990 & $\begin{array}{l}\mathrm{Cu}^{2+} \text {-binding membrane sialoglycoprotein involved in protection against } \\
\text { oxidative stress, cell adhesion, differentiation, and survival in the CNS; V } \\
\text { allele overrepresented in women with moderate } \mathrm{TLE}^{31} \text {. }\end{array}$ \\
\hline $\begin{array}{l}\text { PDYN, } \\
\text { prodynorphin }\end{array}$ & $\begin{array}{l}\text { VNTR in the } \\
\text { promoter }\end{array}$ & $\begin{array}{l}\text { Anticonvulsant peptide; low expression allele associated with increased } \\
\text { risk of TLE in patients with family history of seizures }{ }^{23} \text {. }\end{array}$ \\
\hline $\begin{array}{l}\text { SCN1A, } N a_{v} 1.1 \\
N a^{+} \text {Channel alpha } \\
\text { subunit }\end{array}$ & rs6732655 & $\begin{array}{l}\text { Voltage-gated } \mathrm{Na}^{+} \text {channel; mutations reported in a range of } \\
\text { paroxysmal neurological disorders including familial hemiplegic } \\
\text { migraine and rarely in focal epilepsies; locus relates to an all-epilepsy } \\
\text { group }{ }^{22} \text {. }\end{array}$ \\
\hline $\begin{array}{l}\text { PCDH7, } \\
\text { protocadherin } 7\end{array}$ & rs28498976 & $\begin{array}{l}\text { Integral membrane protein with putative function in cell-cell } \\
\text { recognition and adhesion; mutations in other protocadherins, i.e. } \\
\text { PCDH19, cause epilepsy and mental retardation; locus relates to an all- } \\
\text { epilepsy group }{ }^{22} \text {. }\end{array}$ \\
\hline $\begin{array}{l}R O R A, R A R- \\
\text { related orphan } \\
\text { receptor } A\end{array}$ & rs12912233 & $\begin{array}{l}\text { Nuclear hormone receptor; rs } 12912233 \text { alone associated with epilepsy } \\
\text { in Malaysians and having synergistic effect with RORA rs } 880626 \text { and } \\
\text { SCN1A rs3812718 }{ }^{139} \text {. }\end{array}$ \\
\hline $\begin{array}{l}\text { TIMP4, tissue } \\
\text { inhibitor of } \\
\text { metallo- } \\
\text { proteinase } 4\end{array}$ & rs3755724 & $\begin{array}{l}\text { Inflammation-induced factor; associated with susceptibility to focal } \\
\text { epilepsy in Malaysian population }{ }^{140} \text {. }\end{array}$ \\
\hline
\end{tabular}




\section{Glossary}

CBF: Cerebral blood flow

CBV: Cerebral blood volume

CDE: Common data elements

CSF: Cerebrospinal fluid

DNP: Dinucleotide polymorphism

DTI, diffusion tensor imaging

EEG, electroencephalogram

FA, fractional anisotropy

GSH: Glutathione

HFO, high-frequency oscillation

iEC, intracortical (entorhinal cortex)

iHC, intrahippocampal

MEG: magnetencephalography

MRI: magnetic resonance imaging

mTLE: medial temporal lobe epilepsy

mTLE-FS+: Mesial temporal lobe epilepsy with febrile seizures plus

PTE: Posttraumatic epilepsy

PSE: Post stroke epilepsy

PWE: People with epilepsy

SE: status epilepticus

T2: a time constant for the decay of transverse magnetization

TBI: traumatic brain injury

TLE: Temporal lobe epilepsy

VNTR: variable number tandem repeats 


\section{Legends to Figures}

Figure 1. Clinically translatable approaches to identify microstructural imaging biomarkers for epileptogenesis. (A, B) Diffusion tensor imaging (DTI): Directionally-encoded color (DEC) fractional anisotropy (FA)-maps of a control rat (A) and a kainic acid-induced status epilepticus (SE) rat 79 days after SE (B). White arrowheads indicate microstructural changes in hippocampal subfields. (C) Highangular-resolution diffusion imaging (HARDI): DEC FA-map overlaid with visualizations of fiber orientation distribution functions (fODFs) from Q-ball reconstruction of HARDI data from the rat hippocampus. Squares indicate pixels in three representative areas: corpus callosum, dentate gyrus, and CA3b from which enlarged fODFs are shown (two columns on right hand). More complex shape is obtained using the HARDI than DTI, representing the heterogeneity of cellular structures. (D) Phase imaging: Gradient echo phase images of rat brain five months after lateral fluid- percussion induces traumatic brain injury. White arrow indicates microbleeds in the external capsule, and black arrow points at a thalamic calcification. 
Figure 2. Examples of prognostic biomarkers for epileptogenesis utilizing metabolic and excitability measures. (A) Combination of change in seizure threshold and behavioral hyperexcitability determined over 3 weeks following pilocarpine-induced status epilepticus (SE) in rats that did or did not develop epilepsy. Diagnosis of epilepsy was based on continuous video-electroencephalogram monitoring over the subsequent weeks and months (data from ${ }^{83}$ ). ROC analysis using combinatorial parameter derived from the seizure threshold and behavioral score predicted the development of epilepsy. Abbreviations: $A \cup C=$ area under the curve. $(\mathbf{B}, \mathbf{C})$ ROC curves using levels of mins (myoinositol)/Cr (creatine) and GSH (glutathione)/ $\mathrm{Cr}$ as indirect measures of astrogliosis and oxidative stress, respectively, measured by ${ }^{1} \mathrm{H}$-MRS in the hippocampus of controls and rats exposed to pilocarpine-induced SE before epilepsy development differentiate control rats from animals that will develop epilepsy (data was re-analyzed from ${ }^{88}$ ). 
Figure 3. Examples for noninvasive detection of inflammation and neurovascular biomarkers. (A) Positron emission tomography (PET): TSPO PET, using the novel ligand $\left[{ }^{18} \mathrm{~F}\right] \mathrm{GE} 180$, allows longitudinal evaluation of neuroinflammation and reveals microglia activation (black arrows) 7 days after pilocarpine-induced SE in a rat. (B) Severity of blood-brain-barrier leakage after traumatic brain injury (TBI) as a prognostic biomarker for post-traumatic epileptogenesis. Within anatomically defined blood vessels, injection of $\mathrm{Gd}$-based contrast agent results in a rapid increase in magnetic resonance imaging (MRI) T1 signal ( $y$-axis) due to arterial input followed by a signal decrease (washout)(blue line). When signal dynamics within voxels of a brain tissue with intact BBB are analyzed, the T1 signal follows the arterial input, but to a smaller magnitude (black line). After TBI when BBB becomes dysfunctional, the leakage of contrast agent results in a slow increase in T1 signal (red line). The signal change over time can be measured as the slope of increased signal (dashed line) using a linear regression analysis or by measuring the total change in signal intensity compared to pre-injection scan $(\Delta T 1)$. (C) Images from a patient following mild traumatic brain injury (TBI) and concussion. Note the increased slope of the T1 signal change in the injured right temporal lobe. (D) ROC analysis reveals that, indeed, BBB dysfunction in the injury area is a prognostic biomarker of epileptogenesis after TBI with an area under curve (AUC) value of 0.85 (data from ${ }^{116}$ ). 
Figure 4. Schematic of the time-dependence of epileptogenesis related to a set of biomarkers. (A) Depending on the analysis time point (x-axis), the roster of candidate biomarkers (BM) can vary. Also the magnitude of abnormality ( $y$-axis) can differ between the subjects who will eventually develop epilepsy as compared to those who will not. For example, early time points will likely include markers released by damaged neurons, glial cells or vasculature whereas markers of cellular plasticity may become apparent later on. In magnetic resonance imaging, the values of diffusion trace (Df) and T2 also depend on the analysis point, and can be affected by recurrent seizures (asterisk). Understanding the timing of biomarker expression during the disease process has a significant value for the choice of a biomarker as well as the analysis platform (e.g., blood vs. imaging) at a given time point. 
Reference List

1. Perucca E, French J, Bialer M. Development of new antiepileptic drugs: challenges, incentives, and recent advances. Lancet Neurol. 2007; 6: 793-804.

2. Pitkänen A, Immonen R. Epilepsy related to traumatic brain injury. Neurotherapeutics. 2014; 11: 286296.

3. Pitkänen A, Engel J, Jr. Past and present definitions of epileptogenesis and its biomarkers. Neurotherapeutics. 2014; 11: 231-241.

4. Nieh SE, Sherr EH. Epileptic encephalopathies: new genes and new pathways. Neurotherapeutics. 2014; 11: 796-806.

5. Schmidt D, Sillanpaa M. Evidence-based review on the natural history of the epilepsies. Curr.Opin.Neurol. 2012; 25: 159-163.

6. Gaitatzis A, Trimble MR, Sander JW. The psychiatric comorbidity of epilepsy. Acta Neurol.Scand. 2004; 110: $207-220$.

7. Gaitatzis A, Carroll K, Majeed A, Sander W. The epidemiology of the comorbidity of epilepsy in the general population. Epilepsia 2004; 45: 1613-1622.

8. Kandratavicius L, Lopes-Aguiar C, Bueno-Junior LS, Romcy-Pereira RN, Hallak JE, Leite JP. Psychiatric comorbidities in temporal lobe epilepsy: possible relationships between psychotic disorders and involvement of limbic circuits. Rev.Bras.Psiquiatr. 2012; 34: 454-466.

9. Simonato M, Brooks-Kayal AR, Engel J, Jr., Galanopoulou AS, Jensen FE, Moshe SL, O'Brien TJ, Pitkänen A, Wilcox KS, French JA. The challenge and promise of anti-epileptic therapy development in animal models. Lancet Neurol. 2014; 13: 949-960.

10. Noebels J. Pathway-driven discovery of epilepsy genes. Nat.Neurosci. 2015; 18: 344-350.

11. Kauffman MA, Levy EM, Consalvo D, Mordoh J, Kochen S. GABABR1 (G1465A) gene variation and temporal lobe epilepsy controversy: new evidence. Seizure. 2008; 17: 567-571.

12. Xi B, Chen J, Yang L, Wang W, Fu M, Wang C. GABBR1 gene polymorphism(G1465A)isassociated with temporal lobe epilepsy. Epilepsy Research 2011; 96: 58-63.

13. Gambardella A, Manna I, Labate A, Chifari R, La RA, Serra P, Cittadella R, Bonavita S, Andreoli V, Lepiane E, Sasanelli F, Di CA, Zappia M, Tedeschi G, Aguglia U, Quattrone A. GABA(B) receptor 1 polymorphism (G1465A) is associated with temporal lobe epilepsy. Neurology 2003; 60: 560563.

14. Wang $X$, Sun $W$, Zhu X, Li L, Wu X, Lin H, Zhu S, Liu A, Du T, Liu Y, Niu N, Wang Y, Liu Y. Association between the gamma-aminobutyric acid type $B$ receptor 1 and 2 gene polymorphisms and 
mesial temporal lobe epilepsy in a Han Chinese population. Epilepsy Research 2008; 81: 198203.

15. Pernhorst K, Raabe A, Niehusmann P, van Loo KM, Grote A, Hoffmann P, Cichon S, Sander T, Schoch S, Becker AJ. Promoter variants determine gamma-aminobutyric acid homeostasis-related gene transcription in human epileptic hippocampi. Journal of Neuropathology and Experimental Neurology 2011; 70: 1080-1088.

16. Haerian BS, Baum L, Kwan P, Cherny SS, Shin JG, Kim SE, Han BG, Tan HJ, Raymond AA, Tan CT, Mohamed Z. Contribution of GABRG2 Polymorphisms to Risk of Epilepsy and Febrile Seizure: a Multicenter Cohort Study and Meta-analysis. Mol.Neurobiol. 2015.

17. Balan S, Sathyan S, Radha SK, Joseph V, Radhakrishnan K, Banerjee M. GABRG2, rs211037 is associated with epilepsy susceptibility, but not with antiepileptic drug resistance and febrile seizures. Pharmacogenet.Genomics 2013; 23: 605-610.

18. Darrah SD, Miller MA, Ren D, Hoh NZ, Scanlon JM, Conley YP, Wagner AK. Genetic variability in glutamic acid decarboxylase genes: associations with post-traumatic seizures after severe TBI. Epilepsy Research 2013; 103: 180-194.

19. Stefulj J, Bordukalo-Niksic T, Hecimovic H, Demarin V, Jernej B. Epilepsy and serotonin (5HT): variations of 5HT-related genes in temporal lobe epilepsy. Neuroscience Letters 2010; 478: 29-31.

20. Manna I, Labate A, Gambardella A, Forabosco P, La RA, Le PE, Aguglia U, Quattrone A. Serotonin transporter gene (5-Htt): association analysis with temporal lobe epilepsy. Neuroscience Letters 2007; 421: 52-56.

21. Li J, Lin H, Zhu X, Li L, Wang X, Sun W, Wu X, Liu A, Niu F, Wang Y, Liu Y. Association study of functional polymorphisms in serotonin transporter gene with temporal lobe epilepsy in Han Chinese population. Eur.J.Neurol. 2012; 19: 351-353.

22. International League Against Epilepsy Consortium on Complex Epilepsies. Genetic determinants of common epilepsies: a meta-analysis of genome-wide association studies. Lancet Neurol. 2014; 13: 893-903.

23. Stogmann E, Zimprich A, Baumgartner C, ull-Watschinger S, Hollt V, Zimprich F. A functional polymorphism in the prodynorphin gene promotor is associated with temporal lobe epilepsy. Ann.Neurol. 2002; 51: 260-263.

24. Scher Al, Wu H, Tsao JW, Blom HJ, Feit P, Nevin RL, Schwab KA. MTHFR C677T genotype as a risk factor for epilepsy including post-traumatic epilepsy in a representative military cohort. Journal of Neurotrauma 2011; 28: 1739-1745.

25. Lv RJ, He JS, Fu YH, Zhang YQ, Shao XQ, Wu LW, Lu Q, Jin LR, Liu H. ASIC1a polymorphism is associated with temporal lobe epilepsy. Epilepsy Research 2011; 96: 74-80.

26. Zhang B, Chen M, Yang H, Wu T, Song C, Guo R. Evidence for involvement of the CD40/CD40L system in post-stroke epilepsy. Neurosci Lett. 2014; 567: 6-10. 
27. Kanemoto K, Kawasaki J, Yuasa S, Kumaki T, Tomohiro O, Kaji R, Nishimura M. Increased frequency of interleukin-1beta-511T allele in patients with temporal lobe epilepsy, hippocampal sclerosis, and prolonged febrile convulsion. Epilepsia 2003; 44: 796-799.

28. Kanemoto K, Kawasaki J, Miyamoto T, Obayashi H, Nishimura M. Interleukin (IL)1beta, IL-1alpha, and IL-1 receptor antagonist gene polymorphisms in patients with temporal lobe epilepsy. Ann.Neurol. 2000; 47: 571-574.

29. Salzmann A, Perroud N, Crespel A, Lambercy C, Malafosse A. Candidate genes for temporal lobe epilepsy: a replication study. Neurol.Sci. 2008; 29: 397-403.

30. Liu Z, Yin X, Liu L, Tao H, Zhou H, Ma G, Cui L, Li Y, Zhang S, Xu Z, Yao L, Cai Z, Zhao B, Li K. Association of KEAP1 and NFE2L2 polymorphisms with temporal lobe epilepsy and drug resistant epilepsy. Gene 2015; 571: 231-236.

31. Labate A, Manna I, Gambardella A, Le PE, La RA, Condino F, Cittadella R, Aguglia U, Quattrone A. Association between the M129V variant allele of PRNP gene and mild temporal lobe epilepsy in women. Neuroscience Letters 2007; 421: 1-4.

32. Buono RJ, Lohoff FW, Sander T, Sperling MR, O'Connor MJ, Dlugos DJ, Ryan SG, Golden GT, Zhao H, Scattergood TM, Berrettini WH, Ferraro TN. Association between variation in the human KCNJ10 potassium ion channel gene and seizure susceptibility. Epilepsy Research 2004; 58: 175183.

33. Heuser K, Nagelhus EA, Tauboll E, Indahl U, Berg PR, Lien S, Nakken S, Gjerstad L, Ottersen OP. Variants of the genes encoding AQP4 and Kir4.1 are associated with subgroups of patients with temporal lobe epilepsy. Epilepsy Research 2010; 88: 55-64.

34. Lv RJ, He JS, Fu YH, Shao XQ, Wu LW, Lu Q, Jin LR, Liu H. A polymorphism in CALHM1 is associated with temporal lobe epilepsy. Epilepsy Behav. 2011; 20: 681-685.

35. Zhu WY, Jiang P, He X, Cao LJ, Zhang LH, Dang RL, Tang MM, Xue Y, Li H. Contribution of NRG1 Gene Polymorphisms in Temporal Lobe Epilepsy. Journal of Child Neurology 2015.

36. Shen N, Zhu X, Lin H, Li J, Li L, Niu F, Liu A, Wu X, Wang Y, Liu Y. Role of BDNF Val66Met functional polymorphism in temporal lobe epilepsy. International Journal of Neurosciences 2015: 1-6.

37. Jamali S, Salzmann A, Perroud N, Ponsole-Lenfant M, Cillario J, Roll P, Roeckel-Trevisiol N, Crespel A, Balzar J, Schlachter K, Gruber-Sedlmayr U, Pataraia E, Baumgartner C, Zimprich A, Zimprich F, Malafosse A, Szepetowski P. Functional variant in complement $C 3$ gene promoter and genetic susceptibility to temporal lobe epilepsy and febrile seizures. PLoS.One. 2010; 5.

38. Bartel DP. MicroRNAs: genomics, biogenesis, mechanism, and function. Cell 2004; 116: 281-297.

39. Jimenez-Mateos EM, Henshall DC. Epilepsy and microRNA. Neuroscience 2013; 238: 218-229.

40. Wang J, Tan L, Tan L, Tian Y, Ma J, Tan CC, Wang HF, Liu Y, Tan MS, Jiang T, Yu JT. Circulating microRNAs are promising novel biomarkers for drug-resistant epilepsy. Sci.Rep. 2015; 5: 10201. 
41. Aronica E, Fluiter K, Iyer A, Zurolo E, Vreijling J, van Vliet EA, Baayen JC, Gorter JA. Expression pattern of miR-146a, an inflammation-associated microRNA, in experimental and human temporal lobe epilepsy. European Journal of Neuroscience 2010; 31: 1100-1107.

42. Kaalund SS, Veno MT, Bak M, Moller RS, Laursen H, Madsen F, Broholm H, Quistorff B, Uldall P, Tommerup N, Kauppinen S, Sabers A, Fluiter K, Moller LB, Nossent AY, Silahtaroglu A, Kjems J, Aronica E, Tumer Z. Aberrant expression of miR-218 and miR-204 in human mesial temporal lobe epilepsy and hippocampal sclerosis-convergence on axonal guidance. Epilepsia 2014; 55: 2017-2027.

43. Miller-Delaney SF, Bryan K, Das S, McKiernan RC, Bray IM, Reynolds JP, Gwinn R, Stallings RL, Henshall DC. Differential DNA methylation profiles of coding and non-coding genes define hippocampal sclerosis in human temporal lobe epilepsy. Brain 2015; 138: 616-631.

44. Zucchini S, Marucci G, Paradiso B, Lanza G, Roncon P, Cifelli P, Ferracin M, Giulioni M, Michelucci R, Rubboli $\mathrm{G}$, Simonato $M$. Identification of miRNAs differentially expressed in human epilepsy with or without granule cell pathology. PLoS.One. 2014; 9: e105521.

45. Alvarez-Erviti L, Seow Y, Yin H, Betts C, Lakhal S, Wood MJ. Delivery of siRNA to the mouse brain by systemic injection of targeted exosomes. Nat.Biotechnol. 2011; 29: 341-345.

46. Haqqani AS, Delaney CE, Tremblay TL, Sodja C, Sandhu JK, Stanimirovic DB. Method for isolation and molecular characterization of extracellular microvesicles released from brain endothelial cells. Fluids Barriers.CNS. 2013; 10: 4.

47. Jin XF, Wu N, Wang L, Li J. Circulating microRNAs: a novel class of potential biomarkers for diagnosing and prognosing central nervous system diseases. Cell Mol.Neurobiol. 2013; 33: 601-613.

48. Wang J, Yu JT, Tan L, Tian Y, Ma J, Tan CC, Wang HF, Liu Y, Tan MS, Jiang T, Tan L. Genome-wide circulating microRNA expression profiling indicates biomarkers for epilepsy. Sci Rep. 2015; 5: 9522.

49. Gorter JA, Iyer A, White I, Colzi A, van Vliet EA, Sisodiya S, Aronica E. Hippocampal subregion-specific microRNA expression during epileptogenesis in experimental temporal lobe epilepsy. Neurobiol.Dis. 2014; 62: 508-520.

50. Roncon P, Soukupova M, Binaschi A, Falcicchia C, Zucchini S, Ferracin M, Langley SR, Petretto E, Johnson MR, Marucci G, Michelucci R, Rubboli G, Simonato M. MicroRNA profiles in hippocampal granule cells and plasma of rats with pilocarpine-induced epilepsy - comparison with human epileptic samples. Sci.Rep. 2015; 5: 14143.

51. McDonald JS, Milosevic D, Reddi HV, Grebe SK, geciras-Schimnich A. Analysis of circulating microRNA: preanalytical and analytical challenges. Clin.Chem. 2011; 57: 833-840.

52. Choy M, Dube CM, Patterson K, Barnes SR, Maras P, Blood AB, Hasso AN, Obenaus A, Baram TZ. A novel, noninvasive, predictive epilepsy biomarker with clinical potential. Journal of Neuroscience 2014; 34: 8672-8684. 
53. Immonen R, Kharatishvili I, Gröhn O, Pitkänen A. MRI biomarkers for post-traumatic epileptogenesis. J Neurotrauma 2013; 30: 1305-1309.

54. Lewis DV, Shinnar S, Hesdorffer DC, Bagiella E, Bello JA, Chan S, Xu Y, MacFall J, Gomes WA, Moshe SL, Mathern GW, Pellock JM, Nordli DR, Jr., Frank LM, Provenzale J, Shinnar RC, Epstein LG, Masur D, Litherland C, Sun S. Hippocampal sclerosis after febrile status epilepticus: the FEBSTAT study. Ann.Neurol. 2014; 75: 178-185.

55. Laitinen T, Sierra A, Pitkänen A, Gröhn O. Diffusion tensor MRI of axonal plasticity in the rat hippocampus. Neuroimage. 2010; 51: 521-530.

56. Sierra A, Gröhn O, Pitkänen A. Imaging microstructural damage and plasticity in the hippocampus during epileptogenesis. Neuroscience 2015.

57. Lehto L, Sierra A, Corum CA, Zhang J, Idiyatullin D, Pitkänen A, Garwood M, Gröhn O. Detection of calcifications in vivo and ex vivo after brain injury in rat using SWIFT. Neuroimage. 2012; 61: 761-772.

58. Fisher RS, van Emde BW, Blume W, Elger C, Genton P, Lee P, Engel J, Jr. Epileptic seizures and epilepsy: definitions proposed by the International League Against Epilepsy (ILAE) and the International Bureau for Epilepsy (IBE). Epilepsia 2005; 46: 470-472.

59. Fisher RS, Acevedo C, Arzimanoglou A, Bogacz A, Cross JH, Elger CE, Engel J, Jr., Forsgren L, French JA, Glynn M, Hesdorffer DC, Lee BI, Mathern GW, Moshe SL, Perucca E, Scheffer IE, Tomson T, Watanabe M, Wiebe S. ILAE official report: a practical clinical definition of epilepsy. Epilepsia 2014; 55: 475-482.

60. Jacobs J, Staba R, Asano E, Otsubo H, Wu JY, Zijlmans M, Mohamed I, Kahane P, Dubeau F, Navarro V, Gotman J. High-frequency oscillations (HFOs) in clinical epilepsy. Prog.Neurobiol. 2012; 98: 302315.

61. Bragin A, Wilson CL, Almajano J, Mody I, Engel J, Jr. High-frequency oscillations after status epilepticus: epileptogenesis and seizure genesis. Epilepsia 2004; 45: 1017-1023.

62. Bragin A, Engel J, Jr., Wilson CL, Fried I, Mathern GW. Hippocampal and entorhinal cortex highfrequency oscillations $(100--500 \mathrm{~Hz})$ in human epileptic brain and in kainic acid--treated rats with chronic seizures. Epilepsia 1999; 40: 127-137.

63. Andrade-Valenca LP, Dubeau F, Mari F, Zelmann R, Gotman J. Interictal scalp fast oscillations as a marker of the seizure onset zone. Neurology 2011; 77: 524-531.

64. Haegelen C, Perucca P, Chatillon CE, ndrade-Valenca L, Zelmann R, Jacobs J, Collins DL, Dubeau F, Olivier A, Gotman J. High-frequency oscillations, extent of surgical resection, and surgical outcome in drug-resistant focal epilepsy. Epilepsia 2013; 54: 848-857.

65. Weiss SA, Banks GP, McKhann GM, Jr., Goodman RR, Emerson RG, Trevelyan AJ, Schevon CA. Ictal high frequency oscillations distinguish two types of seizure territories in humans. Brain 2013; 136: 3796-3808. 
66. Akiyama T, McCoy B, Go CY, Ochi A, Elliott IM, Akiyama M, Donner EJ, Weiss SK, Snead OC, III, Rutka JT, Drake JM, Otsubo $\mathrm{H}$. Focal resection of fast ripples on extraoperative intracranial EEG improves seizure outcome in pediatric epilepsy. Epilepsia 2011; 52: 1802-1811.

67. Kerber K, Dumpelmann M, Schelter B, Le VP, Korinthenberg R, Schulze-Bonhage A, Jacobs J. Differentiation of specific ripple patterns helps to identify epileptogenic areas for surgical procedures. Clin. Neurophysiol. 2014; 125: 1339-1345.

68. Salami P, Levesque M, Benini R, Behr C, Gotman J, Avoli M. Dynamics of interictal spikes and highfrequency oscillations during epileptogenesis in temporal lobe epilepsy. Neurobiol.Dis. 2014; 67: 97-106.

69. Levesque M, Salami P, Gotman J, Avoli M. Two seizure-onset types reveal specific patterns of highfrequency oscillations in a model of temporal lobe epilepsy. Journal of Neuroscience 2012; 32: 13264-13272.

70. Jacobs J, Vogt C, LeVan P, Zelmann R, Gotman J, Kobayashi K. The identification of distinct highfrequency oscillations during spikes delineates the seizure onset zone better than highfrequency spectral power changes. Clin.Neurophysiol. 2015.

71. Xiang J, Tenney JR, Korman AM, Leiken K, Rose DF, Harris E, Yuan W, Horn PS, Holland K, Loring DW, Glauser TA. Quantification of Interictal Neuromagnetic Activity in Absence Epilepsy with Accumulated Source Imaging. Brain Topogr. 2014.

72. Tenney JR, Fujiwara H, Horn PS, Vannest J, Xiang J, Glauser TA, Rose DF. Low- and high-frequency oscillations reveal distinct absence seizure networks. Ann.Neurol. 2014; 76: 558-567.

73. Xiang J, Luo Q, Kotecha R, Korman A, Zhang F, Luo H, Fujiwara H, Hemasilpin N, Rose DF. Accumulated source imaging of brain activity with both low and high-frequency neuromagnetic signals. Front Neuroinform. 2014; 8: 57.

74. Amiri M, Lina JM, Pizzo F, Gotman J. High Frequency Oscillations and spikes: Separating real HFOs from false oscillations. Clin. Neurophysiol. 2015.

75. Dümpelmann M, Jacobs J, Schulze-Bonhage A. Temporal and spatial characteristics of high frequency oscillations as a new biomarker in epilepsy. Epilepsia 2015; 56: 197-206.

76. Kharatishvili I, Pitkänen A. Posttraumatic epilepsy. Curr Opin Neurol. 2010; 23: 183-188.

77. Rattka M, Brandt C, Bankstahl M, Broer S, Löscher W. Enhanced susceptibility to the GABA antagonist pentylenetetrazole during the latent period following a pilocarpine-induced status epilepticus in rats. Neuropharmacology 2011; 60: 505-512.

78. Bolkvadze T, Pitkänen A. Development of post-traumatic epilepsy after controlled cortical impact and lateral fluid-percussion-induced brain injury in the mouse. J Neurotrauma 2012; 29: 789-812.

79. Rattka M, Brandt C, Löscher W. Do proconvulsants modify or halt epileptogenesis? Pentylenetetrazole is ineffective in two rat models of temporal lobe epilepsy. Eur.J Neurosci 2012; 36: 2505-2520. 
80. Brima T, Otahal J, Mares P. Increased susceptibility to pentetrazol-induced seizures in developing rats after cortical photothrombotic ischemic stroke at P7. Brain Res 2013; 1507: 146-153.

81. Mishra AM, Bai X, Sanganahalli BG, Waxman SG, Shatillo O, Gröhn O, Hyder F, Pitkänen A, Blumenfeld $\mathrm{H}$. Decreased resting functional connectivity after traumatic brain injury in the rat. PLoS One 2014; 9: e95280.

82. Brandt C, Tollner K, Klee R, Broer S, Löscher W. Effective termination of status epilepticus by rational polypharmacy in the lithium-pilocarpine model in rats: Window of opportunity to prevent epilepsy and prediction of epilepsy by biomarkers. Neurobiol Dis. 2015; 75: 78-90.

83. Broer $\mathrm{S}$, Löscher W. Novel combinations of phenotypic biomarkers predict development of epilepsy in the lithium-pilocarpine model of temporal lobe epilepsy in rats. Epilepsy Behav. 2015; 53: 98107.

84. Wieser HG, Bancaud J, Talairach J, Bonis A, Szikla G. Comparative value of spontaneous and chemically and electrically induced seizures in establishing the lateralization of temporal lobe seizures. Epilepsia 1979; 20: 47-59.

85. Barba C, Barbati G, Di GD, Fuggetta F, Papacci F, Meglio M, Colicchio G. Diagnostic yield and predictive value of provoked ictal SPECT in drug-resistant epilepsies. Journal of Neurology 2012; 259: 1613-1622.

86. Barba C, Di GD, Fuggetta F, Colicchio G. Provoked ictal SPECT in temporal and extratemporal drugresistant epileptic patients: comparison of Statistical Parametric Mapping and qualitative analysis. Epilepsy Research 2009; 84: 6-14.

87. So N, Gloor P, Quesney LF, Jones-Gotman M, Olivier A, Andermann F. Depth electrode investigations in patients with bitemporal epileptiform abnormalities. Ann. Neurol. 1989; 25: 423-431.

88. Filibian M, Frasca A, Maggioni D, Micotti E, Vezzani A, Ravizza T. In vivo imaging of glia activation using $1 \mathrm{H}$-magnetic resonance spectroscopy to detect putative biomarkers of tissue epileptogenicity. Epilepsia 2012; 53: 1907-1916.

89. Guo Y, Gao F, Wang S, Ding Y, Zhang H, Wang J, Ding MP. In vivo mapping of temporospatial changes in glucose utilization in rat brain during epileptogenesis: an 18F-fluorodeoxyglucose-small animal positron emission tomography study. Neuroscience 2009; 162: 972-979.

90. Shultz SR, Cardamone L, Liu YR, Hogan RE, Maccotta L, Wright DK, Zheng P, Koe A, Gregoire MC, Williams JP, Hicks RJ, Jones NC, Myers DE, O'Brien TJ, Bouilleret V. Can structural or functional changes following traumatic brain injury in the rat predict epileptic outcome? Epilepsia 2013; 54: $1240-1250$.

91. McGinnity CJ, Koepp MJ, Hammers A, Riano Barros DA, Pressler RM, Luthra S, Jones PA, Trigg W, Micallef C, Symms MR, Brooks DJ, Duncan JS. NMDA receptor binding in focal epilepsies. J Neurol.Neurosurg.Psychiatry 2015; 86: 1150-1157. 
92. Syvanen S, Labots $M$, Tagawa $Y$, Eriksson J, Windhorst AD, Lammertsma AA, de Lange EC, Voskuyl RA. Altered GABAA receptor density and unaltered blood-brain barrier transport in a kainate model of epilepsy: an in vivo study using 11C-flumazenil and PET. J Nucl.Med. 2012; 53: 1974-1983.

93. Filiou MD, Arefin AS, Moscato P, Graeber MB. 'Neuroinflammation' differs categorically from inflammation: transcriptomes of Alzheimer's disease, Parkinson's disease, schizophrenia and inflammatory diseases compared. Neurogenetics. 2014; 15: 201-212.

94. Vezzani A, Maroso M, Balosso S, Sanchez MA, Bartfai T. IL-1 receptor/Toll-like receptor signaling in infection, inflammation, stress and neurodegeneration couples hyperexcitability and seizures. Brain Behav.Immun. 2011; 25: 1281-1289.

95. Vezzani A, French J, Bartfai T, Baram TZ. The role of inflammation in epilepsy. Nat.Rev.Neurol. 2011; 7: 31-40.

96. Vezzani A, Aronica E, Mazarati A, Pittman QJ. Epilepsy and brain inflammation. Exp.Neurol. 2013; 244: 11-21.

97. Ravizza T, Balosso S, Vezzani A. Inflammation and prevention of epileptogenesis. Neuroscience Letters 2011; 497: 223-230.

98. Vezzani A, Fujinami RS, White HS, Preux PM, Blumcke I, Sander JW, Löscher W. Infections, inflammation and epilepsy. Acta Neuropathol. 2015.

99. Pulli B, Chen JW. Imaging Neuroinflammation - from Bench to Bedside. J.Clin.Cell Immunol. 2014; 5.

100. Amhaoul H, Staelens S, Dedeurwaerdere S. Imaging brain inflammation in epilepsy. Neuroscience 2014; 279: 238-252.

101. Barry JM, Choy M, Dube C, Robbins A, Obenaus A, Lenck-Santini PP, Scott RC, Baram TZ, Holmes GL. T2 relaxation time post febrile status epilepticus predicts cognitive outcome. Exp.Neurol. 2015;

269: 242-252.

102. Gershen LD, Zanotti-Fregonara P, Dustin IH, Liow JS, Hirvonen J, KreisI WC, Jenko KJ, Inati SK, Fujita M, Morse CL, Brouwer C, Hong JS, Pike VW, Zoghbi SS, Innis RB, Theodore WH. Neuroinflammation in Temporal Lobe Epilepsy Measured Using Positron Emission Tomographic Imaging of Translocator Protein. JAMA Neurol. 2015; 72: 882-888.

103. Pollard JR, Eidelman O, Mueller GP, Dalgard CL, Crino PB, Anderson CT, Brand EJ, Burakgazi E, Ivaturi SK, Pollard HB. The TARC/sICAM5 Ratio in Patient Plasma is a Candidate Biomarker for Drug Resistant Epilepsy. Front Neurol. 2012; 3: 181.

104. Shinnar S, Hesdorffer DC, Nordli DR, Jr., Pellock JM, O'Dell C, Lewis DV, Frank LM, Moshe SL, Epstein LG, Marmarou A, Bagiella E. Phenomenology of prolonged febrile seizures: results of the FEBSTAT study. Neurology 2008; 71: 170-176.

105. Cacheaux LP, Ivens S, David Y, Lakhter AJ, Bar-Klein G, Shapira M, Heinemann U, Friedman A, Kaufer D. Transcriptome profiling reveals TGF-beta signaling involvement in epileptogenesis. Journal of Neuroscience 2009; 29: 8927-8935. 
106. Weissberg I, Wood L, Kamintsky L, Vazquez O, Milikovsky DZ, Alexander A, Oppenheim H, Ardizzone C, Becker A, Frigerio F, Vezzani A, Buckwalter MS, Huguenard JR, Friedman A, Kaufer D. Albumin induces excitatory synaptogenesis through astrocytic TGF-beta/ALK5 signaling in a model of acquired epilepsy following blood-brain barrier dysfunction. Neurobiol Dis. 2015; 78: 115-125.

107. Rodriguez-Baeza A, Reina-de la TF, Poca A, Marti M, Garnacho A. Morphological features in human cortical brain microvessels after head injury: a three-dimensional and immunocytochemical study. Anat.Rec.A Discov.Mol.Cell Evol.Biol. 2003; 273: 583-593.

108. Rigau V, Morin M, Rousset MC, de BF, Lebrun A, Coubes P, Picot MC, Baldy-Moulinier M, Bockaert J, Crespel A, Lerner-Natoli $M$. Angiogenesis is associated with blood-brain barrier permeability in temporal lobe epilepsy. Brain 2007; 130: 1942-1956.

109. van Vliet EA, da Costa AS, Redeker S, van SR, Aronica E, Gorter JA. Blood-brain barrier leakage may lead to progression of temporal lobe epilepsy. Brain 2007; 130: 521-534.

110. Raabe A, Schmitz AK, Pernhorst K, Grote A, von der BC, Urbach H, Friedman A, Becker AJ, Elger CE, Niehusmann $P$. Cliniconeuropathologic correlations show astroglial albumin storage as a common factor in epileptogenic vascular lesions. Epilepsia 2012; 53: 539-548.

111. Wei EP, Hamm RJ, Baranova Al, Povlishock JT. The long-term microvascular and behavioral consequences of experimental traumatic brain injury after hypothermic intervention. $J$ Neurotrauma 2009; 26: 527-537.

112. Ding G, Jiang Q, Li L, Zhang L, Gang ZZ, Ledbetter KA, Ewing JR, Li Q, Chopp M. Detection of BBB disruption and hemorrhage by Gd-DTPA enhanced MRI after embolic stroke in rat. Brain Res 2006; 1114: 195-203.

113. Veksler R, Shelef I, Friedman A. Blood-brain barrier imaging in human neuropathologies. Arch Med.Res 2014; 45: 646-652.

114. Tomkins O, Shelef I, Kaizerman I, Eliushin A, Afawi Z, Misk A, Gidon M, Cohen A, Zumsteg D, Friedman A. Blood-brain barrier disruption in post-traumatic epilepsy. J Neurol.Neurosurg.Psychiatry 2008; 79: 774-777.

115. Pavlovsky L, Seiffert E, Heinemann U, Korn A, Golan H, Friedman A. Persistent BBB disruption may underlie alpha interferon-induced seizures. J Neurol. 2005; 252: 42-46.

116. Tomkins O, Feintuch A, Benifla M, Cohen A, Friedman A, Shelef I. Blood-brain barrier breakdown following traumatic brain injury: a possible role in posttraumatic epilepsy. Cardiovasc. Psychiatry Neurol. 2011; 2011: 765923.

117. Pitkänen A, McIntosh TK. Animal models of post-traumatic epilepsy. Journal of Neurotrauma 2006; 23: 241-261.

118. Pitkänen A, Immonen RJ, Gröhn $\mathrm{OH}$, Kharatishvili I. From traumatic brain injury to posttraumatic epilepsy: what animal models tell us about the process and treatment options. Epilepsia 2009; 50 Suppl 2: 21-29. 
119. Löscher W, Brandt C. Prevention or modification of epileptogenesis after brain insults: experimental approaches and translational research. Pharmacol.Rev 2010; 62: 668-700.

120. Pitkänen A, Kharatishvili I, Narkilahti S, Lukasiuk K, Nissinen J. Administration of diazepam during status epilepticus reduces development and severity of epilepsy in rat. Epilepsy Research 2005; 63: 27-42.

121. Shrot S, Ramaty E, Biala Y, Bar-Klein G, Daninos M, Kamintsky L, Makarovsky I, Statlender L, Rosman Y, Krivoy A, Lavon O, Kassirer M, Friedman A, Yaari Y. Prevention of organophosphate-induced chronic epilepsy by early benzodiazepine treatment. Toxicology 2014; 323: 19-25.

122. Ravizza T, Gagliardi B, Noe F, Boer K, Aronica E, Vezzani A. Innate and adaptive immunity during epileptogenesis and spontaneous seizures: evidence from experimental models and human temporal lobe epilepsy. Neurobiol.Dis. 2008; 29: 142-160.

123. Dyhrfjeld-Johnsen J, Berdichevsky Y, Swiercz W, Sabolek H, Staley KJ. Interictal spikes precede ictal discharges in an organotypic hippocampal slice culture model of epileptogenesis. $J$

Clin.Neurophysiol 2010; 27: 418-424.

124. Erdmann J. All aboard: Will molecular tumor boards help cancer patients? Nat Med. 2015; 21: 655-656.

125. McDermott JE, Wang J, Mitchell H, Webb-Robertson BJ, Hafen R, Ramey J, Rodland KD. Challenges in Biomarker Discovery: Combining Expert Insights with Statistical Analysis of Complex Omics Data. Expert.Opin.Med.Diagn. 2013; 7: 37-51.

126. Atluri G, Padmanabhan K, Fang G, Steinbach M, Petrella JR, Lim K, Macdonald A, III, Samatova NF, Doraiswamy PM, Kumar V. Complex biomarker discovery in neuroimaging data: Finding a needle in a haystack. Neuroimage.Clin. 2013; 3: 123-131.

127. Humpel C. Identifying and validating biomarkers for Alzheimer's disease. Trends Biotechnol. 2011; 29: 26-32.

128. Rosen C, Hansson O, Blennow K, Zetterberg H. Fluid biomarkers in Alzheimer's disease - current concepts. Mol.Neurodegener. 2013; 8: 20.

129. Di Battista AP, Buonora JE, Rhind SG, Hutchison MG, Baker AJ, Rizoli SB, az-Arrastia R, Mueller GP. Blood Biomarkers in Moderate-To-Severe Traumatic Brain Injury: Potential Utility of a MultiMarker Approach in Characterizing Outcome. Front Neurol. 2015; 6: 110.

130. Milward EA, Moscato P, Riveros C, Johnstone DM. Beyond statistics: a new combinatorial approach to identifying biomarker panels for the early detection and diagnosis of Alzheimer's disease. J Alzheimers.Dis. 2014; 39: 211-217.

131. Gao Z, Roy A, Tan M. Multistage adaptive biomarker-directed targeted design for randomized clinical trials. Contemp.Clin.Trials 2015; 42: 119-131.

132. Labate A, Cherubini A, Tripepi G, Mumoli L, Ferlazzo E, Aguglia U, Quattrone A, Gambardella A. White matter abnormalities differentiate severe from benign temporal lobe epilepsy. Epilepsia 2015; 56: 1109-1116. 
133. Wagner AK, Miller MA, Scanlon J, Ren D, Kochanek PM, Conley YP. Adenosine A1 receptor gene variants associated with post-traumatic seizures after severe TBI. Epilepsy Research 2010; 90 : 259-272.

134. Diaz-Arrastia R, Gong Y, Fair S, Scott KD, Garcia MC, Carlile MC, Agostini MA, Van Ness PC. Increased risk of late posttraumatic seizures associated with inheritance of APOE epsilon4 allele. Arch Neurol. 2003; 60: 818-822.

135. Diamond ML, Ritter AC, Failla MD, Boles JA, Conley YP, Kochanek PM, Wagner AK. IL-1beta associations with posttraumatic epilepsy development: a genetics and biomarker cohort study. Epilepsia 2014; 55: 1109-1119.

136. Yang $\mathrm{H}$, Song $Z$, Yang GP, Zhang BK, Chen M, Wu T, Guo R. The ALDH2 rs671 polymorphism affects poststroke epilepsy susceptibility and plasma 4-HNE levels. PLoS One 2014; 9: e109634.

137. Guo Y, Baum LW, Sham PC, Wong V, Ng PW, Lui CH, Sin NC, Tsoi TH, Tang CS, Kwan JS, Yip BH, Xiao SM, Thomas GN, Lau YL, Yang W, Cherny SS, Kwan P. Two-stage genome-wide association study identifies variants in CAMSAP1L1 as susceptibility loci for epilepsy in Chinese. Hum.Mol.Genet. 2012; 21: 1184-1189.

138. Johnson MR, Behmoaras J, Bottolo L, Krishnan ML, Pernhorst K, Santoscoy PL, Rossetti T, Speed D, Srivastava PK, Chadeau-Hyam M, Hajji N, Dabrowska A, Rotival M, Razzaghi B, Kovac S, Wanisch K, Grillo FW, Slaviero A, Langley SR, Shkura K, Roncon P, De T, Mattheisen M, Niehusmann P, O'Brien TJ, Petrovski S, von LM, Hoffmann P, Eriksson J, Coffey AJ, Cichon S, Walker M, Simonato M, Danis B, Mazzuferi M, Foerch P, Schoch S, De P, V, Kaminski RM, Cunliffe VT, Becker AJ, Petretto E. Systems genetics identifies Sestrin 3 as a regulator of a proconvulsant gene network in human epileptic hippocampus. Nat.Commun. 2015; 6: 6031.

139. Haerian BS, Sha'ari HM, Tan HJ, Fong CY, Wong SW, Ong LC, Raymond AA, Tan CT, Mohamed Z. RORA gene rs12912233 and rs880626 polymorphisms and their interaction with SCN1A rs3812718 in the risk of epilepsy: a case-control study in Malaysia. Genomics 2015; 105: 229-236.

140. Haerian BS, Sha'ari HM, Fong CY, Tan HJ, Wong SW, Ong LC, Raymond AA, Tan CT, Mohamed Z. Contribution of TIMP4 rs3755724 polymorphism to susceptibility to focal epilepsy in Malaysian Chinese. Journal of Neuroimmunology 2015; 278: 137-143. 